\title{
HIGH TEMPERATURE ION IRRADIATION EFFECTS IN MAX PHASE
}

\author{
CERAMICS -D.W. Clark ${ }^{1}$, S.J. Zinkle ${ }^{1,2}$, M.K. Patel ${ }^{1}$, C.M. Parish ${ }^{2}$ \\ 1 University of Tennessee, Knoxville, TN 37996 USA \\ ²Oak Ridge National Laboratory, Oak Ridge, TN 37831 USA
}

\section{ABSTRACT}

The family of layered carbides and nitrides known as MAX phase ceramics combine many attractive properties of both ceramics and metals due to their nanolaminate crystal structure and are promising potential candidates for application in future nuclear reactors. This investigation examines the effects of energetic heavy ion (5.8 MeV Ni) irradiations on polycrystalline samples of $\mathrm{Ti}_{3} \mathrm{SiC}_{2}, \mathrm{Ti}_{3} \mathrm{AlC}_{2}$, and $\mathrm{Ti}_{2} \mathrm{AlC}$. The irradiation conditions consisted of midrange ion doses between 10 and 30 displacements per atom at temperatures of 400 and $700{ }^{\circ} \mathrm{C}$, conditions relevant to application in future nuclear reactors and a relatively un-explored regime for this new class of materials. Following irradiation, a comprehensive analysis of radiation response properties was compiled using grazing incidence $X$-ray diffraction (XRD), nanoindentation, scanning electron microcopy (SEM), and transmission electron microscopy (TEM). In all cases, XRD and TEM analyses confirm the materials remain fully crystalline although the intense atomic collisions induce significant damage and disorder into the layered crystalline lattice. Xray diffraction and nanoindentation show this damage is manifest in anisotropic swelling and hardening at all conditions and in all materials, with the aluminum based MAX phase exhibiting significantly more damage than their silicon counterpart. In all three materials there is little damage dependence on dose, suggesting saturation of radiation damage at levels below 10 displacements per atom, and significantly less retained damage at higher temperatures, suggesting radiation defect annealing. SEM surface analysis showed significant grain boundary cracking and loss of damage tolerance properties in the aluminum-based MAX phase irradiated at $400^{\circ} \mathrm{C}$, but not in the silicon counterpart. TEM analysis of select samples suggest that interstitials are highly mobile while vacancies are immobile and that all three materials are in the so-called point defect swelling regime between 400 and $700{ }^{\circ} \mathrm{C}$. All results are consistent with previous work involving traditional and MAX phase ceramics. Results show that the aluminum MAX phases are not fit for application near $400^{\circ} \mathrm{C}$ and that the silicon MAX phase is overall more damage tolerant.

Key words: radiation effects, radiation hardening; lattice parameter swelling, defect clusters

${ }^{*}$ corresponding author contact information: D.W. Clark, University of Tennessee, Knoxville, TN 37996 USA, email dclark35@vols.utk.edu. 


\section{INTRODUCTION}

Currently, one of the largest technical challenges in the nuclear energy industry is with respect to neutron radiation-induced degradation of materials properties. The materials used in existing nuclear reactors provide the basis for and greatly influence the reliability, safety, and economics of these reactors. Power up-rates, reactor lifetime extensions, and fuel integrity are but a few specific examples that are directly affected by material concerns. Material challenges are also expected to be major roadblocks to the development of future fission (Generation IV) reactors and fusion reactors, which generally require materials to reliably operate at higher temperatures and/or radiation damage levels compared to existing water-cooled commercial power reactors. Due to this, there is a renewed interest in advanced and innovative nuclear materials research $[1,2]$.

A promising but as yet unproven class of material known as MAX Phase Ceramics (or simply MAX Phases) represents a relatively new class of solids best described as thermodynamically stable nanolaminates. MAX Phases are a family of layered compounds with chemical formula $M_{n+1} A X_{n}$, where $M$ is an early transition metal, $A$ is an element from the IIIA or IVA groups, $\mathrm{X}$ is carbon or nitrogen, and $n=1,2$, or 3 [3-7]. The atomic stacking is based on a layered hexagonal close packed (HCP) crystal structure with alternating layers of close-packed M-atoms and X-atoms filling octahedral sites (comprising a formula identical to those found in the rock salt structure of $M X$ binaries), and layers of pure A-group elements. Due to their unique crystal structure, MAX phases combine many attractive properties of both ceramics and metals. These properties include high temperature stability, high stiffness, good electrical and thermal conductivity, fracture toughness, thermal shock resistance, and machinability [3-7]. Certain MAX phases also promise good oxidation resistance and chemical compatibility [8]. Due the MAX phases' unique combination of high temperature stability, stiffness, conductivity, corrosion resistance, machinability, and possible radiation tolerance, they are currently being considered as a possible advanced nuclear material for a variety of applications, including current generation fission light water reactors (LWRs), future generation (Gen. IV) fission, and proposed fusion reactors. Proposed applications include: oxidation-resistant spray-on coating for cladding, piping, and steam generator tubes in current LWR systems, structural material piping and core internals in advanced fission reactors due to high chemical compatibility with select coolants such as molten lead and sodium, high temperature, high dose cladding material for future generation fission reactors, and high temperature, high dose structural materials for future generation fission and fusion reactor systems $[9,10]$.

Due to their relatively recent discovery, the radiation response mechanisms of the MAX phase ceramics are still largely unexplored, with studies only emerging in publication within the last half decade. Though the majority of studies to date have only focused on the low dose, low temperature irradiation regime, some basic conclusions regarding their radiation response can still be drawn. The first and most basic conclusion is that the MAX phases are expected to follow physical and mechanical property radiationinduced change trends similar to those seen in traditional HCP ceramics. Secondly, previous experiments suggest that the MAX phases are generally resistant to 
amorphization up to doses of $\sim 25$ displacements per atom (dpa) following irradiation between 25 and $500{ }^{\circ} \mathrm{C}$. This has been confirmed using selected area electron diffraction (SAED) and transmission electron microscopy (TEM) imaging techniques in $\mathrm{Ti}_{3} \mathrm{SiC}_{2}$ and $\mathrm{Ti}_{3} \mathrm{AlC}_{2}$ at $\sim 25 \mathrm{dpa}$ [11] and using SAED, TEM, x-ray diffraction (XRD), and nanoindentation for $\mathrm{Ti}_{3} \mathrm{SiC}_{2}$ at lower damage levels ( $\left.\sim 5 \mathrm{dpa}\right)$ for multiple irradiation conditions between $\mathrm{RT}$ and $500{ }^{\circ} \mathrm{C}$. Since radiation-induced amorphization typically only occurs at relatively low temperatures where interstitial point defects are immobile [12], amorphization is not expected to be an issue at fission and fusion reactor-relevant temperatures of $\sim 300-1000{ }^{\circ} \mathrm{C}[3,10,11,13-18]$. Additionally, there is no evidence of void formation in $\mathrm{Ti}_{3} \mathrm{SiC}_{2}$ and $\mathrm{Ti}_{3} \mathrm{AlC}_{2}$ up to $500{ }^{\circ} \mathrm{C}$ and $25 \mathrm{dpa}$ [11], suggesting that vacancies are immobile below $500^{\circ} \mathrm{C}$ (or else void nucleation and growth is strongly suppressed). These two factors hint that 25 and $500^{\circ} \mathrm{C}$ in MAX phases correspond to temperatures above recovery Stage I (onset temperature for interstitial motion) and below recovery Stage III (onset temperature for vacancy motion), respectively [12, 19]. Finally, XRD, TEM and nanoindentation results suggest that the MAX phases have a positive correlation between temperature and radiation damage recovery. This is manifest in a progressive decrease in crystalline lattice disorder and defect cluster density with increasing irradiation temperature by XRD and TEM [13-16, 20], as well as a pronounced decrease in nanoindentation hardness at higher irradiation temperatures $[10,18]$. Collectively, these observations are consistent with mobile interstitials and immobile vacancies ("point defect swelling" regime). One of the characteristics of the point defect swelling regime is that damage accumulation approaches a saturation level at doses above 0.1 - 1 dpa due to the high concentration of immobile vacancies that serve as recombination centers for the migrating interstitials [12]. Hence, it is hypothesized that the MAX phases may have substantial radiation resistance up to relatively high damage levels between 25 and $500{ }^{\circ} \mathrm{C}$ or higher.

\section{Experimental Procedure}

\subsection{Material}

The MAX phase bulk samples used in this experiment were synthesized at Drexel University; a detailed explanation of the synthesis and processing conditions is discussed elsewhere [21, 22], but an abbreviated description is as follows. The $\mathrm{Ti}_{2} \mathrm{AlC}$ samples were prepared by pouring pre-reacted Ti2AIC powders (Kanthal, Hallstahammar, Sweden) into graphite dies, which were loaded into a vacuum hot press and hot pressed for $4 \mathrm{~h}$ under a load corresponding to a stress of $40 \mathrm{MPa}$ and a vacuum pressure of $10-1 \mathrm{~Pa}$ at a temperature of $1300^{\circ} \mathrm{C}$. The $\mathrm{Ti}_{3} \mathrm{AlC}_{2}$ samples were fabricated by ball milling stoichiometric mixtures of pre-reacted $\mathrm{Ti}_{2} \mathrm{AIC}$ and TiC powders (Alfa Aeser, Ward Hill, MA, USA) for $24 \mathrm{~h}$ and in turn, hot pressed at $1400{ }^{\circ} \mathrm{C}$ for $4 \mathrm{~h}$. Finally, the $\mathrm{Ti}_{3} \mathrm{SiC}_{2}$ samples were prepared by ball milling stoichiometric mixtures of $\mathrm{Ti}$, $\mathrm{Si}$, and $\mathrm{C}$ powders (Alfa Aesar, Ward Hill, MA, USA) for $24 \mathrm{~h}$, which were then hot pressed at $1450{ }^{\circ} \mathrm{C}$ for $4 \mathrm{~h}[20]$.

In preparation for the experiment, the bulk samples were received from Drexel were subsequently sectioned with a low speed diamond saw, cut into $\sim 3 \mathrm{~mm}$ diameter disks, 
ground to $\sim 0.6 \mathrm{~mm}$, and polished using diamond lapping film and colloidal silica suspension on polishing cloth. After the final polishing, the $3 \mathrm{~mm}$ diameter disk samples had a nominal final thickness of $0.55 \mathrm{~mm}$.

\subsection{Irradiations}

The samples were irradiated to midrange doses of 10 and $30 \mathrm{dpa}$, at temperatures of 400 and $700{ }^{\circ} \mathrm{C}$, at the Texas A\&M Accelerator Laboratory using $5.8 \mathrm{MeV} \mathrm{Ni}^{4+}$ ions at a particle flux of $\sim 3 \times 10^{11} / \mathrm{cm}^{2}-\mathrm{s}\left(\sim 1.4 \times 10^{-4} \mathrm{dpa} / \mathrm{s}\right.$ at a midrange depth of $\left.\sim 1.4 \mu \mathrm{m}\right)$. The correlation between ion fluence and dpa was determined using SRIM 2013 with recommendations from Stoller et.al. [23], and an assumed threshold displacement energy of $30 \mathrm{eV}$. A graphic of normalized dpa vs. ion penetration depth for all three materials can be seen in Fig. 1, with the selected area for post-irradiation analysis defined by the red box. Irradiated regions associated with the peak damage region ( 3 $\mu \mathrm{m}$ depth) were avoided in the post irradiation analysis due to potential complications associated with implanted $\mathrm{Ni}$ ions. Similarly, regions near the surface were avoided due to potential artifacts. A list of irradiation conditions and corresponding ion fluences for the four dose-temperature conditions can be seen in Table 1.

\subsection{Characterization Techniques}

Following irradiation, small scale analysis techniques were used to analyze the $<3 \mu \mathrm{m}$ deep, thin irradiated region. These techniques included grazing incidence $\mathrm{X}$-ray diffraction (GXRD), nanoindentation, scanning electron microscopy (SEM) and TEM.

To determine lattice parameter swelling in irradiated MAX phases, GXRD was performed using the Philips X'Pert Pro MRD was used. Due to the small irradiated sample size and aperture constraints, samples were mounted on single crystal silicon substrate to provide a nearly zero background test environment. The incident beam angle, $\omega$, was calculated using the computer program HighScore Plus to achieve an approximate maximum beam depth of $1.5 \mu \mathrm{m}$, which corresponds to the depth for the nominal midrange dose. The incident beam configuration included a $\mathrm{Cu} k \alpha \mathrm{X}$-ray tube and parabolic mirror to obtain a parallel beam of X-ray in order to negate the sample height effects. The diffracted beam side included a $0.27^{\circ}$ parallel plate collimator and a Xe proportional detector to detect the diffracted X-rays. The measurements were performed in a $2 \theta$ mode with the tube fixed at an angle $\omega$ with respect to the surface of the sample. The diffraction patterns were collected within a $2 \theta$ range of $30-80^{\circ}$ with a step size of $0.02^{\circ}$ and a step time of 6 seconds in order to analyze diffraction patterns, the computer programs CMPR and Highscore Plus were used to find peak positions and match inorganic crystal structure database (ICSD) diffraction patterns respectively [24, 25].

An Agilent nanoindenter with a Berkovich diamond indenter tip was used to examine the change of hardness and elastic modulus of the irradiated surface region. The indents were completed using a constant load rate of $500 \mu \mathrm{N} / \mathrm{s}$ (continuous stiffness mode) and preformed up to a depth $1100 \mathrm{~nm}$. Optimized indentation positions were manually 
chosen using an optical microscope attached to the instrument. The areas considered optimized were those that appeared to be optically pristine and devoid of flaws, including scratches, pull-out, secondary phases, grain boundaries, contamination, etc. To avoid the effect of strain fields, the distance between indents, large scratches, and sample edges was at least $50 \mu \mathrm{m}$. Approximately twenty indents were made per sample to obtain a good statistical average. Hardness and elastic modulus were then determined as functions of indentation depth using the software associated with indenter [26]. Since the elastic strain from indentation extends to depths that may be 510 times the indenter depth [27], it was crucial to determine the transition point between the irradiated and substrate regions for quantitative analysis of the ion irradiated nanoindentation data. This indentation transition depth was determined by plotting the square of the hardness versus inverse indent depth, as recommended in the Nix-Gao Model [28]. The indentation transition depth was determined to be approximately 400 $\mathrm{nm}$ for all of the ion irradiated samples, i.e., about $1 / 8$ of the calculated extent of the ion irradiation region. In order to minimize errors associated with low indentation depths and obtain good statistics, hardness and elastic modulus changes were calculated across all indents averaged from a 200-400 nm indentation depth.

The surfaces of the as-polished and ion irradiated samples were examined using secondary electron detection mode in a Zeiss Gemini Scanning Electron Microscope using a voltage of $10 \mathrm{kV}$ to examine the effect of irradiation and nanoindentation.

TEM cross-sectional foils were prepared using a FEI V400ACE Focused Ion Beam (30 $\mathrm{keV} \mathrm{Ga}$ lon source) to create samples that were approximately $15 \mu \mathrm{m}$ long by $10 \mu \mathrm{m}$ deep with a viewing thickness of approximately $50-100 \mathrm{~nm}$. The final polish on these samples was done using a $2 \mathrm{kV}, 8 \mathrm{pA}$ probe to help eliminate any residual damage/amorphous regions created during initial milling. An FEI Tecnai T20 Transmission Electron Microscope (200 keV, $\mathrm{LaB}_{6}$ emitter, FEI Twin lens) was used to image defects in select samples. For the initial analysis, a traditional two-beam condition was used with a beam direction of approximately $\langle 11 \overline{2} 0\rangle$, as determined by electron diffraction and Kikuchi patterns. This allowed for imaging along the approximate diffraction vectors $(g)$ of $\langle 0001\rangle$ and $\langle 1 \overline{1} 00\rangle /\langle 01 \overline{1} 0\rangle$, corresponding to the characteristic basal and prismatic directions of the HCP crystal structure. As no large voids were observed in the traditional two-beam imaging condition, under- and overfocus Fresnel contrast imaging under weak kinematic diffraction conditions was used to search for the existence of any small voids in the materials [29, 30].

\section{Results}

\subsection{SEM Surface Analysis}

Figures 2, 3, and 4 show as-irradiated sample surfaces at the four irradiation conditions for $\mathrm{Ti}_{3} \mathrm{AlC}_{2}, \mathrm{Ti}_{2} \mathrm{AIC}$, and $\mathrm{Ti}_{3} \mathrm{SiC}_{2}$ respectively. From Figs. 2 and 3 , it can be seen that both of the aluminum based MAX phases show significant surface cracking at both doses following irradiation at $400{ }^{\circ} \mathrm{C}$, while no significant cracking was observed at both 
doses following irradiation at $700{ }^{\circ} \mathrm{C}$. The cracking appeared to be exclusively associated with grain boundaries. In contrast, the surface images of the silicon based MAX phase shown in Fig. 4 did not exhibit significant surface cracking at either the low $\left(400^{\circ} \mathrm{C}\right)$ or high $\left(700^{\circ} \mathrm{C}\right)$ temperature irradiation conditions for either dose.

The $\mathrm{Ti}_{3} \mathrm{AlC}_{2} 30 \mathrm{dpa}-700{ }^{\circ} \mathrm{C}$ (Fig. 2(d)) sample had significant contamination build up on the surface of the sample, believed to be hydrocarbon formation caused from outgassing of silver paste used to fasten the sample to the substrate for the ion irradiations. Subsequent cross section analysis showed that the contaminant film was $100-200 \mathrm{~nm}$ at its thickest. This surface contamination is believed to be responsible for slight difference between the $\mathrm{Ti}_{3} \mathrm{AlC}_{2} 10 \mathrm{dpa}-700{ }^{\circ} \mathrm{C}$ and $30 \mathrm{dpa}-700{ }^{\circ} \mathrm{C}$ diffraction patterns and the unexpected decrease in hardness of the $\mathrm{Ti}_{3} \mathrm{AlC}_{2} 30 \mathrm{dpa}-700{ }^{\circ} \mathrm{C}$ data point discussed later in this section.

The degree of surface cracking was quantified for the irradiated samples to determine if there was any discernable dependence of cracking on material composition, dose, or temperature. Randomly oriented lines were drawn across surface images. The number of crack intersections were counted for a large number of lines and divided by the total line length to provide a quantitative measure of the cracked grain boundary area per unit volume $\left(\mathrm{S}_{\mathrm{v}}\right)$ using the formula $\mathrm{S}_{\mathrm{v}}=2 \mathrm{~N}$ where $\mathrm{N}$ is the average number of cracked grain boundary intersections per unit length of randomly drawn surface lines [31]. This crack density parameter does not take into account other crack features that might have an impact on structural integrity, such as average crack length, but was used to quantify overall cracking severity. The measured $S_{v}$ values for samples irradiated at $400^{\circ} \mathrm{C}$ are summarized in Table 2. As can be seen, there is no discernable difference in the linear crack densities between the same aluminum MAX phase materials at different doses at $400{ }^{\circ} \mathrm{C}$, though the $\mathrm{Ti}_{2} \mathrm{AlC}$ does appear to have a slightly higher crack density than the $\mathrm{Ti}_{3} \mathrm{AlC}_{2}$. As noted earlier, surface cracking was not observed in $\mathrm{Ti}_{3} \mathrm{SiC}_{2}$ for either dose at $400{ }^{\circ} \mathrm{C}$, and no surface cracking was observed in any of the three materials irradiated at either dose at $700^{\circ} \mathrm{C}$

\subsection{GXRD Analysis}

The GXRD patterns for irradiated $\mathrm{Ti}_{3} \mathrm{AlC}_{2}$ can be seen in Figs. 5 where (a) denotes low dose low temperature $\left(10 \mathrm{dpa}-400^{\circ} \mathrm{C}\right)$, (b) low dose high temperature $\left(10 \mathrm{dpa}-700{ }^{\circ} \mathrm{C}\right)$, (d) high dose low temperature ( $30 \mathrm{dpa}-400^{\circ} \mathrm{C}$ ), (e) high dose high temperature (30 dpa$700{ }^{\circ} \mathrm{C}$ ), and (c\&f) pristine conditions. The graphics are presented such that, going from bottom to top, it can be seen there is a significant temperature dependence on the disruption of the diffraction patterns. It can also be seen, by going left to right, there is very little variation in the irradiated diffraction patterns with increasing dose from $10 \mathrm{dpa}$ to $30 \mathrm{dpa}$, with the sole exception of the high dose, high temperature $\left(30 \mathrm{dpa}-700{ }^{\circ} \mathrm{C}\right)$ sample that was believed to have an artifact associated with surface contamination accrued during the irradiation. There was no evidence of amorphization for any of the irradiation conditions. Additionally, the deduced lattice parameter changes for all four irradiation conditions yielded virtually identical results for samples irradiated at the same 
temperature but different doses. For these reasons, and in order to save time and cost, the remaining two materials, $\mathrm{Ti}_{2} \mathrm{AIC}$ and $\mathrm{Ti}_{3} \mathrm{SiC}_{2}$, were only analyzed using GXRD at the high dose condition ( $30 \mathrm{dpa}$ ), with only the high dose $\mathrm{Ti}_{3} \mathrm{AlC}_{2}$ patterns being used for comparison. The GXRD patterns for $\mathrm{Ti}_{2} \mathrm{AlC}$ and $\mathrm{Ti}_{3} \mathrm{SiC}_{2}$ at (a) $30 \mathrm{dpa}-70{ }^{\circ} \mathrm{C}$, (b) 30 dpa-700 ${ }^{\circ} \mathrm{C}$, and (c) pristine conditions are shown in Figs. 6 and 7 respectively.

In all cases, the ion irradiation resulted in modification of the diffraction pattern through reduction of the peak heights, broadening, and shifting of the peak locations, signifying pronounced effects of irradiation on the detailed crystal structures. Similar to the results for $\mathrm{Ti}_{3} \mathrm{AlC}_{2}$ (Fig. 5), there was no evidence of amorphization in $\mathrm{Ti}_{2} \mathrm{AIC}$ (Fig. 6) and $\mathrm{Ti}_{3} \mathrm{SiC}_{2}$ (Fig. 7) after 30 dpa midrange dose ( $\sim 75$ dpa peak damage) for either the 400 or $700{ }^{\circ} \mathrm{C}$ irradiation temperatures. In all three materials, there is significantly less disruption of the diffraction pattern at the $30 \mathrm{dpa}-700{ }^{\circ} \mathrm{C}$ condition then at the $30 \mathrm{dpa}$ $400{ }^{\circ} \mathrm{C}$ condition. Consequently, there are only slight differences in the pristine and 30 dpa-700 ${ }^{\circ} \mathrm{C}$ diffraction patterns for all three materials, with the surface-contaminated (cf. Fig. 2d) $\mathrm{Ti}_{3} \mathrm{AlC}_{2} 30 \mathrm{dpa}-700{ }^{\circ} \mathrm{C}$ sample exhibiting the most change. Further examinations of the diffraction patterns shows that the $\mathrm{Ti}_{3} \mathrm{SiC}_{2}$ irradiated samples appear to show the least disturbance due to irradiation, with very little peak shift and only slight peak reduction and broadening. Consequently, only minor diffraction peaks are lost for this material at the $30 \mathrm{dpa}-400{ }^{\circ} \mathrm{C}$ condition. In stark contrast, both aluminum based MAX phases appear to have suffered significant damage at the 30 dpa- $400{ }^{\circ} \mathrm{C}$ irradiation. Only the largest diffraction peaks are still visible in $\mathrm{Ti}_{2} \mathrm{AIC}$ and both the both aluminum MAX phases exhibit peaks that are not prevalent in the pristine samples, suggesting large shifts and/or emergence of new peaks.

Manipulation of the ICSD diffraction pattern peak positions to match the observed data using Highscore Plus yielded nominal lattice parameter changes for each material. A summary of these calculated values can be seen in Table 3 . The most significant effect was the development of anisotropic lattice parameter changes due to irradiation.

In all three MAX phases, there was a pronounced increase in the basal (c-direction) lattice parameter (C-LP) at the $30 \mathrm{dpa}-400{ }^{\circ} \mathrm{C}$ irradiation condition, with a less significant increase of the C-LP in the $\mathrm{Ti}_{3} \mathrm{AlC}_{2}$ and only minimal change for the $\mathrm{Ti}_{2} \mathrm{AIC}$, and $\mathrm{Ti}_{3} \mathrm{SiC}_{2}$ at the $30 \mathrm{dpa}-700{ }^{\circ} \mathrm{C}$ irradiation condition. At the $30 \mathrm{dpa}-400{ }^{\circ} \mathrm{C}$ condition, the $\mathrm{Ti}_{2} \mathrm{AlC}$ exhibited the highest c-LP swelling, with an increase from 13.41(5) $\AA$ to 13.74(8) $\AA$, an increase of approximately $2.46 \%$. The $\mathrm{Ti}_{3} \mathrm{SiC}_{2}$ exhibited the least amount of c-LP swelling for irradiation at $400{ }^{\circ} \mathrm{C}$, with an increase of 17.65(4) $\AA$ to $17.72(6) \AA$, corresponding to a relative increase of approximately $0.40 \%$. For the $30 \mathrm{dpa}-400{ }^{\circ} \mathrm{C}$ irradiation condition, $\mathrm{Ti}_{3} \mathrm{AlC}_{2}$ fell in between with an increase of 18.54(6) $\AA$ to $18.74(9) \AA$, or $1.08 \%$. For the $30 \mathrm{dpa}-700{ }^{\circ} \mathrm{C}$ condition, only the $\mathrm{Ti}_{3} \mathrm{AlC}_{2}$ exhibited lattice parameter swelling, which was limited to $0.38 \%$, from 18.54(6) $\AA$ to 18.61 (3) $\AA$. Both the Ti2AIC, and $\mathrm{Ti}_{3} \mathrm{SiC}_{2}$ exhibited slight contraction from pristine c-LP values at the $30 \mathrm{dpa}-700{ }^{\circ} \mathrm{C}$ condition.

With respect to the prismatic (a-direction) lattice parameter (a-LP), both aluminum MAX phases exhibit a slight a-LP reduction at the $30 \mathrm{dpa}-400{ }^{\circ} \mathrm{C}$ condition with minimal change at the $30 \mathrm{dpa}-700{ }^{\circ} \mathrm{C}$ condition, while the silicon based MAX phase exhibits a 
slight a-LP increase at both irradiation conditions. The Ti2AIC shows the most a-LP contraction at the $30 \mathrm{dpa}-400{ }^{\circ} \mathrm{C}$ irradiation condition, decreasing from 3.061 (8) $\AA$ to $3.04(1) \AA$, a change of $0.69 \%$. The $\mathrm{Ti}_{3} \mathrm{AlC} \mathrm{C}_{2}$ exhibits a less exaggerated reduction, going from $3.0735(7) \AA$ to $3.065(5) \AA$, a $0.28 \%$ change at the $30 \mathrm{dpa}-400{ }^{\circ} \mathrm{C}$ condition. Both aluminum MAX phases exhibit only slight change at the $30 \mathrm{dpa}-700^{\circ} \mathrm{C}$ irradiation condition (absolute change of $0.2 \%$ or less). The silicon based MAX phase exhibits a slight increase in the a-LP at both the $30 \mathrm{dpa}-400^{\circ} \mathrm{C}$ and $30 \mathrm{dpa}-700^{\circ} \mathrm{C}$ irradiation conditions, going from 3.059(4) $\AA$ to 3.069 (3) $\AA$ and $3.067(3) \AA$, a $0.33 \%$ and $0.26 \%$ respective increase. A plot of both the relative (a) C-LP and (b) a-LP shifts post irradiation can be seen in Fig. 8. It should be noted that large differences in c-axis and a-axis swelling can produce pronounced strains at randomly oriented grain boundaries and can result in grain boundary cracking depending on the magnitude of anisotropic swelling and material parameters.

In order to obtain a quantitative estimation of the critical differential strain required for grain boundary cracking, the analytical technique developed by Clarke et al. in their 1964 studies on grain boundary cracking in neutron irradiated $\mathrm{BeO}$ was used [32]. Their analysis considered the misfit strain introduced at grain boundaries from anisotropic lattice expansion that led to grain boundary cracking. Spontaneous cracking is predicted to occur for misfit strains above a critical value given by Eq. (1), where the critical differential strain $(\varepsilon)$ is related to the grain boundary surface energy in the absence of anisotropic strain $(\gamma)$, the elastic modulus $(E)$, and the average grain diameter $(2 l)$.

$$
\varepsilon \sim\left(\frac{24 \gamma}{E l}\right)^{\frac{1}{2}}
$$

The grain diameters for each of the investigated materials were measured by Tallman et al. [20] and were independently confirmed using Electron Back Scattering diffraction in the present study. The nominal average grain diameter for $\mathrm{Ti}_{3} \mathrm{AlC}_{2}, \mathrm{Ti}_{2} \mathrm{AlC}_{\mathrm{C}}$, and $\mathrm{Ti}_{3} \mathrm{SiC}_{2}$ were determined to be 16(6), 10(4), and 8(3) $\mu \mathrm{m}$ respectively. The elastic moduli were taken from literature $[5,7]$ and the grain boundary surface energy was assumed to be $1.5 \mathrm{~N} / \mathrm{m}$, a typical value for $\mathrm{Al}_{2} \mathrm{O}_{3}$. A comparison of the calculated critical differential strain and the experimental differential strains for the three materials irradiated at the two temperature conditions can be seen in Table 4. As can be seen, Eq. (1) predicts only the low temperature irradiated aluminum base MAX phase samples experienced differential swelling sufficient to induce grain boundary cracking (an order of magnitude larger than the predicted critical value), supporting the conclusion that anisotropic swelling is the cause of grain boundary cracking in the $400^{\circ} \mathrm{C}$ irradiated aluminum MAX phases.

\subsection{Nano-Indentation Analysis}

The evolution of hardness as a function of irradiation dose averaged over indent depths of 200-400 nm for the three MAX phase materials can be seen for irradiation temperatures of (a) $400{ }^{\circ} \mathrm{C}$ and (b) $700^{\circ} \mathrm{C}$ in Fig. 9. It can be seen that for all three 
materials at both $400{ }^{\circ} \mathrm{C}$ and $700{ }^{\circ} \mathrm{C}$, there is significant increase in hardness from the pristine samples to the irradiated samples, due to radiation induced defects. Of the three materials, $\mathrm{Ti}_{3} \mathrm{AlC}_{2}$ exhibits the most radiation hardening up to a maximum of approximately $1.9 \times$ for the low temperature irradiations and $1.6 \times$ for high temperature irradiations. In comparison, $\mathrm{Ti}_{3} \mathrm{SiC}_{2}$ exhibits the least amount of hardening at both the low and high temperature irradiation conditions with a maximum of approximately $1.4 \times$ and $1.2 \times$ respectively. The $\mathrm{Ti}_{2} \mathrm{AlC}$ falls in between the other materials with a maximum relative hardening of approximately $1.6 \times$ at the low temperature condition and $1.4 \times$ at the high temperature condition. Additionally, it can be seen that there is little variation in hardness from samples irradiated to a midrange dose of $10 \mathrm{dpa}$ and those irradiated to a midrange dose of $30 \mathrm{dpa}$, for both irradiation temperatures. This suggests a saturation effect in the radiation induced hardening has occurred for a dose of $10 \mathrm{dpa}$ and higher.

The effect of irradiation temperature on hardness for all three materials at a midrange dose of (a) $10 \mathrm{dpa}$ and (b) $30 \mathrm{dpa}$ can be seen in Fig. 10. From this figure, it becomes apparent that there is significantly less hardening at an irradiation temperature of $700^{\circ} \mathrm{C}$ than at an irradiation temperature of $400^{\circ} \mathrm{C}$ for all three materials. This suggest a positive correlation between irradiation temperature and reduction in radiation induced hardness.

The evolution of the relative elastic modulus of the three materials as a function of irradiation dose averaged over $200-400 \mathrm{~nm}$ can be seen in Fig. $11 \mathrm{for}$ (a) $400{ }^{\circ} \mathrm{C}$ and (b) $700{ }^{\circ} \mathrm{C}$, and as a function of irradiation temperature in Fig. 12 for (a) 10 dpa midrange dose and (b) 30 dpa midrange dose. Irradiated materials typically exhibit a slight change in the elastic modulus due to defect formation and lattice parameter changes that saturates after relatively small $(0.1-1 \mathrm{dpa})$ amounts of damage [33, 34]. Upon examination, it appears that all of the irradiated samples follow this trend, with the majority of samples experiencing a slight elastic modulus increase of approximately $10 \%$. The exception to this trend are the low temperature irradiations of the aluminum MAX phases, in which $\mathrm{Ti}_{3} \mathrm{AlC}_{2}$ exhibited little to no change in elastic modulus and $\mathrm{Ti}_{2} \mathrm{AIC}$ exhibited a slight decrease in elastic modulus of about $6 \%$.

SEM examination was used following indentation hardness testing to observe the surface features associated with nanoindentation. Imaging the surface indents, it was seen that for the $400{ }^{\circ} \mathrm{C}$ irradiated aluminum MAX phase surfaces (those that experienced cracking), the indenter produced significant corner cracking. For the uncracked aluminum and all the silicon based MAX phase surfaces, the indentation did not induce corner cracking and features analogous to that of indentation on pristine MAX phase, such as slip bands/delamination and push-out, are observed [35]. Figures 13, 14 , and 15 show indents in surfaces irradiated at (a) $10 \mathrm{dpa}-400{ }^{\circ} \mathrm{C}$ and (b) $10 \mathrm{dpa}-700$ ${ }^{\circ} \mathrm{C}$ conditions in $\mathrm{Ti}_{3} \mathrm{AlC}_{2}, \mathrm{Ti}_{2} \mathrm{AIC}$, and $\mathrm{Ti}_{3} \mathrm{SiC}_{2}$ respectively. 


\subsection{TEM Microstructural Analysis}

TEM cross section analysis was used to examine microstructural defects in selected samples. The samples chosen for TEM analysis were those considered to be most relevant to the questions raised by the previous SEM surface, $X R D$, and nanoindentation analysis, the most important of which are "why are the aluminum based MAX phases cracking at the $400{ }^{\circ} \mathrm{C}$ irradiation conditions and not cracking following 700 ${ }^{\circ} \mathrm{C}$ irradiation", as well as "are vacancies sufficiently mobile to produce observable cavity formation in either the aluminum or silicon based MAX phase at $700{ }^{\circ} \mathrm{C}$ ". Assuming that both the aluminum MAX phases would exhibit qualitatively similar microstructural evolution under irradiation (due to their qualitatively similar response in terms of lattice parameter changes, hardening, and surface cracking propensity), the samples deemed as highest priority for TEM analysis were $\mathrm{Ti}_{3} \mathrm{AlC}_{2} 30 \mathrm{dpa}-400{ }^{\circ} \mathrm{C}$, $\mathrm{Ti}_{3} \mathrm{AlC}_{2} 30 \mathrm{dpa}-700{ }^{\circ} \mathrm{C}$, and $\mathrm{Ti}_{3} \mathrm{SiC}_{2} 30 \mathrm{dpa}-700^{\circ} \mathrm{C}$.

A low-magnification TEM micrograph of the $\mathrm{Ti}_{3} \mathrm{AlC}_{2} 30 \mathrm{dpa}-400{ }^{\circ} \mathrm{C}$ cross-section foil and SAED results for the underlying unirradiated region (2) can be seen in Fig. 16. The green arrow represents the direction of ion irradiation, which penetrated to a depth of approximately $3 \mu \mathrm{m}$, as displayed by the white line denoting the separation of the irradiated area and non-irradiated bulk. This is consistent with SRIM ion penetration depth calculations provided above. SAED was performed on the unirradiated region (2), well beyond the range of the ions (displayed as an inset in the upper right of Fig. 17), in order to determine both the phase and orientation of the grain. Comparing experimental and ICSD diffraction pattern spacing, the grain was confirmed to be the nominal $\mathrm{Ti}_{3} \mathrm{AlC}_{2}$ phase and the beam direction was determined to be $\mathrm{B} \sim\langle 11 \overline{2} 0\rangle$. This low magnification analysis was completed again for both the $30 \mathrm{dpa}-700^{\circ} \mathrm{C} \mathrm{Ti}_{3} \mathrm{AlC}_{2}$ and $\mathrm{Ti}_{3} \mathrm{SiC}_{2}$ samples.

Subsequently, standard two-beam conditions were used to obtain bright field and dark field images using the $\mathrm{g} \sim\langle 0001\rangle$ (basal) and $\mathrm{g} \sim\langle 1 \overline{1} 00\rangle$ (prism) diffraction vectors for both the unirradiated (2) and irradiated (1) regions of $\mathrm{Ti}_{3} \mathrm{AlC}_{2}$ irradiated to $30 \mathrm{dpa}$ at $400{ }^{\circ} \mathrm{C}$, as shown in Figs. 17 and 18 respectively. It is important to note that the irradiated region (1) was analyzed at a depth of $\sim 1.5 \mu \mathrm{m}$, corresponding to the nominal midrange dose of $30 \mathrm{dpa}$. As can be seen in both the $\langle 0001\rangle$ and $\langle 1 \overline{1} 00\rangle \mathrm{g}$ vectors in Fig. 17, a low density of large defect clusters typical of unirradiated materials exist in the pristine region. On the contrary, for both $\mathrm{g}$ vectors in the $400^{\circ} \mathrm{C}$ irradiated region shown in Fig. 18 , there is a large density of "black spots" or small defect clusters, with a distinct lack of voids (the latter was confirmed using under- and over-focusing Fresnel techniques). The very high density of defect clusters visible in these images suggest a saturation of interstitial point defect clusters in the irradiated area induced through nuclear displacements.

Standard two-beam conditions were also used to obtain bright field and dark field images for $\mathrm{g} \sim\langle 0001\rangle$ (basal) and $\mathrm{g} \sim\langle 1 \overline{1} 00\rangle$ (prism) diffraction vector directions for $\mathrm{Ti}_{3} \mathrm{AlC}_{2}$ and $\mathrm{Ti}_{3} \mathrm{SiC}_{2}$ irradiated to a midrange dose of $30 \mathrm{dpa}$ at $700{ }^{\circ} \mathrm{C}$, shown in Figs 19 and 20. Again, Fresnel imaging showed a distinct lack of voids, suggesting that vacancy mobility is limited in both the aluminum and silicon based MAX phase at $700{ }^{\circ} \mathrm{C}$ 
(or else void nucleation and growth is otherwise inhibited). However, contrary to the $400{ }^{\circ} \mathrm{C}$ irradiated $\mathrm{Ti}_{2} \mathrm{AlC}$, the irradiated microstructures did not contain a large density of small cluster defects, but instead consisted of a lower density of large defect clusters for both the $\langle 0001\rangle$ and $\langle 1 \overline{1} 00\rangle$ diffraction vectors. In the $700^{\circ} \mathrm{C} \mathrm{Ti}_{3} \mathrm{AlC}_{2}$, these grouped defect clusters appeared to form a hatched or diamond pattern for $\mathrm{g}=\langle 0001\rangle$ and $\mathrm{a}$ striped pattern for $\mathrm{g}=\langle 0001\rangle\langle 1 \overline{1} 00\rangle$. Upon inspection, the defects appear to be comprised of smaller basal defects that coalesce in a stacking sequence at \pm 35 degree angles from the basal direction. The fact that these defects can also be seen for the prism zone axis suggest a prismatic component as well. Full characterization of these defect clusters is needed before any definitive conclusions as to their nature can be draw, but the general features of significantly coarser defect cluster microstructure suggest a higher mobility of interstitial defects at this higher irradiation temperature.

Similar to the $700{ }^{\circ} \mathrm{C}$ irradiated $\mathrm{Ti}_{3} \mathrm{AlC}_{2}$, the $\mathrm{Ti}_{3} \mathrm{SiC}_{2}$ irradiated microstructure did not contain a large density of small cluster defects, but instead consisted of a lower density of larger defect clusters at both the basal and prism viewing zone axis. However, these grouped defects did not form similar self-organized patterns seen in the $\mathrm{Ti}_{3} \mathrm{AlC}_{2}$, but instead exhibited what appears to be large stacking faults along the basal plane and dislocation loops along the prism axis. Again, full characterization of these defect clusters is still needed before any definitive conclusions as to their nature can be drawn, but the general irradiation damage seen in $\mathrm{Ti}_{3} \mathrm{SiC}_{2}$ appears to be less pronounced than that observed in $\mathrm{Ti}_{3} \mathrm{AlC}_{2}$, and is consistent with the GXRD and nanoindentation results.

\section{Discussion}

From the GXRD patterns it is apparent that all three materials maintain crystallinity following irradiation at all four conditions, and this was verified in selected TEM examinations of three specimens. However, it can clearly be seen from the GXRD patterns collected that considerable disorder has been introduced to the materials, especially at the low temperature irradiation conditions, and is manifested in the peak position shifts, reduction in intensities, and broadening, as well as what could possibly be the appearance of new peaks. When discussing the GXRD data, it is important to note that characteristic diffraction peaks help determine phase composition of materials, and that irradiation can have profound effects on the formation or dissolution of phases by alteration of the stability of those phase. The most direct way in which irradiation can alter phase stability is by causing localized enrichment or depletion of atoms, such that solubility limits or phase boundaries are crossed. Irradiation can also dissolve phases by recoil dissolution, cause disordering by creating anti-site defects, and lead to nucleation and growth of distinct phases. Due to its complex bonding and crystal structure, the potential effect of radiation induced phase change on MAX phases is a significant concern with regard to radiation tolerance, especially when regarding secondary phases. Complexities during synthesis, in which secondary phases such as MX and higher order MAX phases tend to compete with the target MAX phase if conditions are not closely monitored, and with its peritectic dissociation at high temperatures, in which the material does not melt congruently but instead dissociates 
into different phases, suggests there may be problems with phase stabilities in an extreme radiation environment. Prior researchers have used Rietveld refinement fitting to claim that MAX phases tend to revert to TiC under irradiation [20] while other researchers use the appearance of new diffraction peaks as evidence of a new, disordered phase under irradiation (so called $\beta$-phase), of which little is currently known $[14,17]$. In either case, the microstructural results obtained in this research do not support the prior claims of phase decomposition in irradiated MAX phases. Instead, our microstructural analysis suggests traditional crystalline disorder is produced by intense irradiation, without phase change. As such, the following discussion of XRD results focuses on the causes and consequences of the observed volumetric swelling.

Volumetric expansion through amorphization, point defect, and void swelling/ bubble formation plays a critical role when designing materials for nuclear environments as substantial ( $>5$ vol.\%) dimensional changes are unacceptable for typical structural engineering designs. The temperature intervals of these swelling regimes are defined by so-called defect recovery stages $[12,36]$ and within a given swelling regime the magnitude of swelling can be highly temperature dependent, providing the basis for defining possible temperature application regimes or "operational temperature windows'. A graphic showing the swelling regimes for a typical ceramic $\left(\mathrm{Al}_{2} \mathrm{O}_{3}\right)$ can be seen in Fig. 21. It has been shown that for the three MAX phase materials investigated in this experiment, amorphization and void formation are not an issue between 400 and $700{ }^{\circ} \mathrm{C}$, thus discussion will be limited to trends associated with the so called "point defect swelling" regime. This stage of volumetric swelling is induced through the addition of radiation defects and is prominent between recovery Stage I (onset of interstitial mobility) and Stage III (onset of vacancy mobility), typically observed between $\sim 0.1$ and $\sim 0.3 \mathrm{~T}_{\mathrm{M}}$ [12]. "Point defect swelling" typically reaches a saturation value after doses of $0.1-1 \mathrm{dpa}$, corresponding to the saturation in point defect and defect cluster density for this temperature regime [12]. Lattice dilatation around an interstitial produces a volume change that is typically between one and two atomic volumes, while lattice relaxation around a vacancy produces a slight volume contraction that is typically less than one atomic volume. This leads to slight volumetric expansion for a Frenkel pair, and forms the physical basis for "point defect swelling" in irradiated materials (along with the analogous lattice expansion from small defect clusters and dislocation loops). The magnitude of the point defect swelling is typically about an order of magnitude larger in ceramics compared to metals: saturation linear swelling levels may be on the order of $1 \%$ or larger for irradiated ceramics in the point defect swelling regime $[12,37]$.

The GXRD patterns collected from the ion irradiated MAX phase samples revealed a distortion of lattice parameters (LPs) under ion irradiation for all three compositions. For $\mathrm{Ti}_{3} \mathrm{AlC}_{2}$, four samples at both irradiation doses and temperatures were explored, reveling a lack of lattice parameter dilation on irradiation dose between 10 and $30 \mathrm{dpa}$, suggesting radiation damage saturation occurs at damage levels below $10 \mathrm{dpa}$. Contrary to the weak dose dependence, lattice dilation had a significant dependence on irradiation temperature. For all three materials, the low temperature irradiations produced the largest deviations in both the C-LP and a-LP, with all three materials experiencing an increase or swelling of their c-LP. $\mathrm{Ti}_{2} \mathrm{AlC}$ exhibited the largest increase 
in C-LP, subsequently followed by $\mathrm{Ti}_{3} \mathrm{AlC}_{2}$ and lastly by $\mathrm{Ti}_{3} \mathrm{SiC}_{2}$. For the a-LP at the low irradiation temperatures, both the aluminum MAX phases showed a decrease in a-LP while the silicon MAX phase showed a slight increase in a-LP. Again, the Ti2AIC showed the largest deviation from pristine, with both the $\mathrm{Ti}_{3} \mathrm{AlC}_{2}$ and $\mathrm{Ti}_{3} \mathrm{SiC}_{2}$ had very similar magnitudes of deviation, albeit with opposite signs. For most samples, irradiation at high temperatures resulted in only slight variation of LPs from their pristine values, with the exception being high temperature irradiated $\mathrm{Ti}_{3} \mathrm{AlC}_{2}$, in which there was still noticeable, though not nearly as severe, c-LP swelling. Overall, the c-LP showed more distinct deviation from pristine samples than the a-LP for all three materials at the low temperature irradiations. The results obtained from GXRD strongly suggest that anisotropic swelling is the underlying cause for grain boundary cracking in the $400{ }^{\circ} \mathrm{C}$ irradiated aluminum MAX phases. The significant swelling at lower irradiation temperatures, and the subsequent decrease of swelling as irradiation temperature is increased, are consistent with what is typically observed in irradiated materials in the "point defect swelling" regime where interstitials are mobile but vacancies are immobile $[12,19]$. Furthermore, the lack of dose dependence in lattice parameter swelling suggests that defect saturation is reached at some displacement level beneath the minimum 10 dpa dose analyzed in this study, again congruent with the "point defect swelling" regime, which saturates at low doses ( 0.1-1 dpa). Overall, the temperaturedependent magnitude of the lattice parameter swelling agrees with previous irradiation experiments, as can be seen in Fig. 22 in which swelling data obtained for doses $>0.2$ dpa are plotted. [14-16, 20]. This implies that crystalline damage saturation occurs above $\sim 0.2 \mathrm{dpa}$ in all three MAX phase materials for temperatures $20-700{ }^{\circ} \mathrm{C}$.

When viewing this comprehensive comparison of all relevant lattice parameter swelling information, it becomes apparent that $\mathrm{Ti}_{3} \mathrm{SiC}_{2}$ does indeed exhibit the smallest amount of both c- and a-LP distortion, particularly as irradiation temperature decreases, though more experimental data is required to fully quantify relative swelling behaviors below $\sim 400{ }^{\circ} \mathrm{C}$. Again, the significantly larger anisotropic distortion of LPs in the aluminum based MAX phases at low temperatures is believed to be responsible for the surface/grain boundary cracking of the $400^{\circ} \mathrm{C}$ irradiated samples observed by SEM. As mentioned in the previous section, anisotropic swelling has been seen to cause large stresses at grain boundaries, and depending on grain size and material parameters [38], can result in cracking. This can be seen for many traditional ceramics such as $\mathrm{BeO}, \mathrm{Al}_{2} \mathrm{O}_{3}, \mathrm{SiC}$, and $\mathrm{AIN} \mathrm{[38-43]} \mathrm{and} \mathrm{is} \mathrm{congruent} \mathrm{with} \mathrm{the} \mathrm{strain} \mathrm{to} \mathrm{cracking}$ estimations made in section 3.2.

Finally, total volumetric swelling from lattice parameter changes for all three materials was calculated and compared to volumetric swelling in traditional HCP ceramics as a function of temperature. As can be seen in Fig. 23, the results for total volumetric swelling in the MAX phase materials are comparable with traditional ceramics such as $\mathrm{SiC}$ and $\mathrm{Al}_{2} \mathrm{O}_{3}$ in the point defect swelling regime, with the MAX phases exhibiting slightly less overall swelling. Additionally, it can be seen that the $\mathrm{Ti}_{3} \mathrm{SiC}_{2}$ actually exhibits similar total volumetric swelling to $\mathrm{Ti}_{2} \mathrm{AlC}$, and more volumetric swelling than $\mathrm{Ti}_{3} \mathrm{AlC}_{2}$, yet remained un-cracked at the low temperature irradiation conditions. Therefore, it may be concluded that the observed grain boundary cracking stems from anisotropic swelling effects rather total volumetric swelling. 
The increase in hardness in the irradiated MAX phases could not be attributed to oxide formation or dramatic chemical change at the sample surface, and as such, must be directly related to the formation of irradiation defects, as previously reported in other ceramics [44-49]. Furthermore, this increase in hardness is consistent with the conclusion that the materials are not being amorphized, as that would have led to a drop, rather than increase in hardness [45]. The lack of hardness change between doses at both the low temperature and high temperature irradiation conditions suggest that radiation induced hardness reaches a saturation point somewhere below the $\mathrm{Ni}$ ion fluence level associated with the $10 \mathrm{dpa}$ midrange dose at both $400^{\circ} \mathrm{C}$ and $700{ }^{\circ} \mathrm{C}$. Additionally, the progressive recovery of induced hardness with increasing irradiation temperature suggests radiation defect recombination/annealing for all three materials. The present results are consistent with the general evolution of radiation induced hardness in the "point defect swelling" regime corresponding to temperatures between recovery Stage I (onset of interstitial migration) and recovery Stage III (onset of vacancy migration), wherein hardness is more prominent at lower irradiation temperatures and saturates after small doses $[12,19]$. Additionally, it is congruent with previous nanoindentation results on MAX phase ceramics $[10,18]$. In terms of elastic modulus, the majority of samples underwent a slight increase, with the exceptions being the low temperature irradiation aluminum based MAX phases, which instead underwent a slight decrease in elastic modulus. This effect has been seen in other ceramics where, after low doses, the pinning of dislocations lead to material strengthening and an increase in elastic modulus [39]. From the SEM observations, it should be noted that the outlying samples that experienced a decrease in elastic modulus following irradiation were the materials suffering from grain boundary/surface cracking. Therefore, we conclude grain boundary cracking (associated with high strains at grain boundaries due to anisotropic swelling) may be the direct cause for the decrease in elastic modulus in these samples.

One last topic related to indentation is with respect to the damage tolerance properties of the MAX phases. Vickers or Berkovich indentation in brittle solids traditionally result in sharp cracks emanating from the corners of the indent, which is indicative of low toughness. In pristine MAX phases, instead of crack formation at corners, one typically observes delaminations or slip bands, kinking of individual grains, grain push-outs and pull-outs around the area of indentations [35]. SEM examination of indentations showed that no cracks were induced during indentation in the silicon base MAX phase at any of the four irradiation conditions or in the high temperature irradiated aluminum based MAX phases. It is far from conclusive, but the presence of characteristic sliding features in the materials that did not exhibit corner cracking shows that the MAX phases are still able to confine localized mechanical damage and are reasonably damage tolerant at those conditions, albeit to what extent is still unknown. This can be attributed to the preservation of the typical layered structure of the MAX phases, and agrees with the GXRD results wherein the most heavily disordered structures appeared to be those of the aluminum MAX phases at the low irradiation temperatures. Due to the fact that indentation induced pronounced corner cracking in the low temperature irradiated aluminum MAX phases, it can be suggested that irradiation at these conditions for these materials affected the microstructure in such a way as to decrease the damage tolerance. 
The presented TEM micrographs exhibit several key features that further support the results discussed above. The appearance of a standard crystalline SAED pattern in the irradiated $30 \mathrm{dpa}-400{ }^{\circ} \mathrm{C}$ irradiated $\mathrm{Ti}_{3} \mathrm{AlC}_{2}$, which is arguably one of the most damaged materials confirms that crystallinity is indeed maintained in all three materials at all irradiation conditions. The high density of small defect clusters in the $30 \mathrm{dpa}-400{ }^{\circ} \mathrm{C}$ irradiated $\mathrm{Ti}_{3} \mathrm{AlC}_{2}$ sample implies interstitials are sufficiently mobile to create small defect clusters while the lack of voids up to a dose of $30 \mathrm{dpa}$ implies immobile vacancies at this temperature. This suggests that at $400^{\circ} \mathrm{C}$ all three MAX phase are between recovery Stage I and Stage III, or the so called "point-defect swelling regime.

The micrographs of $30 \mathrm{dpa}-700{ }^{\circ} \mathrm{C}$ irradiated $\mathrm{Ti}_{3} \mathrm{AlC}_{2}$ appear to show large, grouped clusters of small basal plane defects that coalesce at \pm 35 degree step angles. This is analogous to "rafting" of small defect clusters that has been previously observed in metallic materials, such as BBC iron, tungsten, and molybdenum [50-52], and full identification of these defect clusters will require more extensive imaging analysis. In any case, it is clear that the defect clusters are more distinct and with a lower density at $700{ }^{\circ} \mathrm{C}$, leading to the conclusion that interstitials are more mobile than those at the 400 ${ }^{\circ} \mathrm{C}$ irradiation condition. The lack of voids implies that vacancies are still immobile at the $700{ }^{\circ} \mathrm{C}$ irradiation condition.

The micrographs of $30 \mathrm{dpa}-700{ }^{\circ} \mathrm{C}$ irradiated $\mathrm{Ti}_{3} \mathrm{SiC}_{2}$ coincide with the results shown for $\mathrm{Ti}_{3} \mathrm{AlC}_{2}$ irradiated at the same condition in that they show larger, better defined defect clusters with a lower density. Again, these larger defects coupled with the lack of voids implies that interstitials have significantly higher mobility than vacancies at the $700{ }^{\circ} \mathrm{C}$ irradiation conditions in $\mathrm{Ti}_{3} \mathrm{SiC}_{2}$. The lack of "rafting" in the $\mathrm{Ti}_{3} \mathrm{SiC}_{2}$ could be indicative of fundamental differences in radiation response between the aluminum and silicon based MAX phase. However, full identification of these defect clusters through extensive imaging analysis is required before any conclusion can be drawn.

Overall, the micrographs of $30 \mathrm{dpa}-700{ }^{\circ} \mathrm{C}$ irradiated $\mathrm{Ti}_{3} \mathrm{AlC}_{2}$ and $\mathrm{Ti}_{3} \mathrm{SiC}_{2}$, depicting larger, more fully formed defects with a lack of voids suggests that all materials are between recovery Stage I and Stage III at $700^{\circ} \mathrm{C}$. This regime is defined by high interstitial mobility, which allows them to coalesce to form observable defect cluster structures, and the lack of void formation suggests that Stage III recovery, or vacancy mobility, has not been reached. This microstructural evidence suggests that the point defect swelling regime extends between at least 400 and $700{ }^{\circ} \mathrm{C}$ and explains why there is significantly more swelling at lower irradiation temperatures in all three materials. Additionally, these results agree with several studies that suggest amorphization (which occurs for irradiation temperatures below recovery Stage I [12]) during irradiation of MAX phase ceramics is possible only for irradiation temperatures well below room temperature and that voids do not form below $900^{\circ} \mathrm{C}[10,11,13-17,20]$.

Analysis of ion irradiated samples after irradiation to midrange doses of 10 and $30 \mathrm{dpa}$ at 400 and $700{ }^{\circ} \mathrm{C}$ suggests that the aluminum based MAX phases are not well suited for application in extreme nuclear environments at irradiation temperatures near $400{ }^{\circ} \mathrm{C}$. Both $\mathrm{Ti}_{3} \mathrm{AlC}_{2}$ and $\mathrm{Ti}_{2} \mathrm{AlC}$ exhibit severe anisotropic swelling at an irradiation temperature of $400{ }^{\circ} \mathrm{C}$, to the point that the stress becomes large enough to induce grain boundary 
cracking. Additionally, both exhibit significantly more crystalline disruption and radiation hardening than their silicon based counterpart post irradiation at both 400 and $700{ }^{\circ} \mathrm{C}$. Though they are not well suited for application near $400^{\circ} \mathrm{C}$, they might still be potential candidates for very high temperature application $\left(>700^{\circ} \mathrm{C}\right)$ as long as there is a sufficiently large operating temperature regime before the onset of void formation (e.g. if void formation only occurs above $800^{\circ} \mathrm{C}$ ). On the contrary, $\mathrm{Ti}_{3} \mathrm{SiC}_{2}$ exhibits only slight radiation induced swelling at both 400 and $700{ }^{\circ} \mathrm{C}$, with no evidence of cracking. It also exhibits the least amount of crystalline lattice disorder and radiation hardening, and maintains signs of damage tolerance against nanoindentation similar to that of pristine MAX phases, following irradiation at 400 and $700{ }^{\circ} \mathrm{C}$. These results suggest that $\mathrm{Ti}_{3} \mathrm{SiC}_{2}$ is a promising candidate in the $400-700^{\circ} \mathrm{C}$ operating window for application in advanced nuclear fission and fusion reactor environments.

\section{CONCLUSIONS}

Ion irradiated experiments of several MAX phase species to midrange doses of 10 and $30 \mathrm{dpa}$ at 400 and $700^{\circ} \mathrm{C}$ suggest that irradiation leads to substantial disordering of the nano-laminate crystal structure via the induction of radiation defects, but does not produce any signs of amorphization. GXRD and nanoindentation show this damage is manifest in anisotropic swelling and hardening at all conditions and in all materials, with the aluminum based MAX phase exhibiting significantly more damage than their silicon counterpart. In all three materials there is little damage dependence on dose, suggesting saturation of radiation damage at levels below 10 displacements per atom, and a high correlation between residual damage and irradiation temperature, with significantly less damage at higher temperatures, suggesting radiation defect annealing. SEM surface analysis showed significant grain boundary cracking and loss of damage tolerance properties in the aluminum based MAX phase irradiated at $400{ }^{\circ} \mathrm{C}$, but not in the silicon counterpart. TEM analysis of select samples suggests that interstitials are highly mobile while vacancies are immobile and that all three materials are in the socalled "point defect swelling" regime between 400 and $700{ }^{\circ} \mathrm{C}$. All results are consistent with previous work involving traditional and MAX phase ceramics. Results show that the aluminum MAX phase materials are not fit for structural application in irradiation environments near 400 degrees Celsius and that the silicon MAX phase is overall more damage tolerant following high dose irradiation at $400-700{ }^{\circ} \mathrm{C}$.

\section{ACKNOWLEDGMENTS}

This work was sponsored by the U.S. Department of Energy's Office of Fusion Energy Sciences through Oak Ridge National Laboratory's "Structural Materials of Potentially Unique Irradiation Resistance" field work proposal ERAT754, under contract number DE-AC05-00OR22725 with UT-Battelle, LLC. The authors would also like to thank Darin Tallman from Drexel University for supplying the synthesized MAX phase bulk 
materials, Dr. Lin Shao from the Texas A\&M Universities Ion Beam Laboratory for his help performing ion irradiations, Dr. N.A.P. Kiran Kumar from Oak Ridge National Laboratory for his help preparing TEM cross-section foils, and Dr. Maxim Gussev from Oak Ridge National Laboratory and Congyi Li from the University of Tennessee for their help performing and analyzing Nano-indentation data. 


\section{REFERENCES}

1. Zinkle, S.J. and J.T. Busby, Structural materials for fission \& fusion energy. Materials Today, 2009. 12(11): p. 12-19.

2. Zinkle, S.J. and G.S. Was, Materials challenges in nuclear energy. Acta Materialia, 2013. 61(3): p. 735-758.

3. Barsoum, M.W., The $M_{n+1} A X_{n}$ Phases and their Properties, in Ceramics Science and Technology. 2010, Wiley-VCH Verlag GmbH \& Co. KGaA. p. 299-347.

4. Barsoum, M.W., The MN+1AXN phases: A new class of solids: Thermodynamically stable nanolaminates. Progress in Solid State Chemistry, 2000. 28(1-4): p. 201-281.

5. Barsoum, M.W. and M. Radovic, Elastic and Mechanical Properties of the MAX Phases, in Annual Review of Materials Research, Vol 41, D.R. Clarke and P. Fratzl, Editors. 2011. p. 195-227.

6. Radovic, M. and M.W. Barsoum, MAX phases: Bridging the gap between metals and ceramics. American Ceramics Society Bulletin, 2013. 92(3): p. 20-27.

7. Radovic, M., et al., On the elastic properties and mechanical damping of Ti3SiC2, Ti3GeC2, Ti3Si0.5Al0.5C2 and Ti2AlC in the 300-1573 K temperature range. Acta Materialia, 2006. 54(10): p. 2757-2767.

8. Tallman, D.J., B. Anasori, and M.W. Barsoum, A critical review of the oxidation of Ti2AIC, Ti3AIC2 and Cr2AIC in Air. Materials Research Letters, 2013. 1(3): p. 115-125.

9. Hoffman, E.N., et al., MAX phase carbides and nitrides: Properties for future nuclear power plant in-core applications and neutron transmutation analysis. Nuclear Engineering and Design, 2012. 244: p. 17-24.

10. Liu, X.M., et al., Nanoindentation investigation of heavy ion irradiated Ti3(Si,Al)C-2. Journal of Nuclear Materials, 2010. 401(1-3): p. 149-153.

11. Whittle, K.R., et al., Radiation tolerance of $M(n+1) A X(n)$ phases, Ti3AlC2 and Ti3SiC2. Acta Materialia, 2010. 58(13): p. 4362-4368.

12. Zinkle, S.J., Radiation-Induced Effects on Microstructure. Comprehensive Nuclear Materials, Vol 1: Basic Aspects of Radiation Effects in Solids/Basic Aspects of Multi-Scale Modeling, ed. R.J.M. Konings. 2012. 65-98.

13. Bugnet, M., et al., Contribution of core-loss fine structures to the characterization of ion irradiation damages in the nanolaminated ceramic Ti3AlC2. Acta Materialia, 2013. 61(19): p. 7348-7363.

14. Liu, X.M., et al., XRD investigation of ion irradiated Ti3Si0.90Al0.10C2. Nuclear Instruments \& Methods in Physics Research Section B-Beam Interactions with Materials and Atoms, 2010. 268(5): p. 506-512.

15. Nappe, J.C., et al., Microstructural changes induced by low energy heavy ion irradiation in titanium silicon carbide. Journal of the European Ceramic Society, 2011. 31(8): p. 1503-1511.

16. Nappe, J.C., et al., Structural changes induced by heavy ion irradiation in titanium silicon carbide. Journal of Nuclear Materials, 2011. 409(1): p. 53-61.

17. Zhang, L., et al., Damage tolerance of Ti3SiC2 to high energy iodine irradiation. Applied Surface Science, 2012. 258(17): p. 6281-6287. 
18. Marion, L. and I. Monnet, Saturation of irradiation damage in (Ti,Zr)(3)(Si,Al)C-2 compounds. Journal of Nuclear Materials, 2013. 433(1-3): p. 534-537.

19. Was, G.S. and SpringerLink (Online service), Fundamentals of Radiation Materials Science Metals and Alloys. 2007, Springer-Verlag GmbH.,: Berlin Heidelberg.

20. Tallman, D.J., et al., Effect of neutron irradiation on select MAX phases. Acta Materialia, 2015. 85: p. 132-143.

21. Barsoum, M.W. and T. EIRaghy, Synthesis and characterization of a remarkable ceramic: Ti3SiC2. Journal of the American Ceramic Society, 1996. 79(7): p. 1953-1956.

22. Eklund, P., et al., The Mn+1AXn phases: Materials science and thin-film processing. Thin Solid Films, 2010. 518(8): p. 1851-1878.

23. Stoller, R.E., et al., On the use of SRIM for computing radiation damage exposure. Nuclear Instruments \& Methods in Physics Research Section B-Beam Interactions with Materials and Atoms, 2013. 310: p. 75-80.

24. Toby, B., CMPR - a powder diffraction toolkit. Journal of Applied Crystallography, 2005. 38(6): p. 1040-1041.

25. HighScore \& HighScore Plus Quick Start Guide. August 2013; 2nd:[Available from: www.PANalytical.com.

26. Oliver, W.C. and G.M. Pharr, An improved technique for determining hardness and elastic modulus using load and displacement sensing indentation experiments. Journal of Materials Research, 1992. 7(06): p. 1564-1583.

27. Samuels, L.E. and T.O. Mulhearn, An experimental investigation of the deformed zone associated with indentation hardness impressions. Journal of the Mechanics and Physics of Solids, 1957. 5(2): p. 125-134.

28. Nix, W.D. and H. Gao, Indentation size effects in crystalline materials: A law for strain gradient plasticity. Journal of the Mechanics and Physics of Solids, 1998. 46(3): p. 411-425.

29. Jenkins, L. and A. Kirk, Characterisation of radiation damage by Transmission Electron Microscopy. 2000: Taylor \& Francis.

30. Jenkins, M.L., Characterization of Radiation-Damage Microstructures by TEM. Journal of Nuclear Materials, 1994. 216: p. 124-156.

31. DeHoff, R.T., F.N. Rhines, and U.o. Florida, Quantitative microscopy. 1968: McGraw-Hill.

32. Clarke, F.J.P., R.S. Wilks, and D.H. Bowen, Mechanisms of irradiation-induced growth and cracking in beryllia. Journal of Nuclear Materials, 1964. 14: p. 205207.

33. Snead, L.L., et al., Handbook of SiC properties for fuel performance modeling. Journal of Nuclear Materials, 2007. 371(1-3): p. 329-377.

34. Kircher, J.F. and R.E. Bowman, Effects of radiation on materials and components. 1964: Reinhold.

35. El-Raghy, T., et al., Damage Mechanisms around Hardness Indentations in Ti3SiC2. Journal of the American Ceramic Society, 1997. 80(2): p. 513-516.

36. Schilling W. and Sonnenberg K., Recovery of irradiated and quenched metals. Journal of Physics F-Metal Physics, 1973. 3(2): p. 322-350. 
37. Trinkaus, H., Ion beam induced amorphization of crystalline solids: Mechanisms and modeling, in Materials Science Applications of Ion Beam Techniques, A.G. Balogh and G. Walter, Editors. 1997. p. 3-12.

38. Wilks, R.S., Neutron-Induced Damage In $\mathrm{BeO} \mathrm{Al}_{2} \mathrm{O}_{3}$ and $\mathrm{MgO}$ - a Review. Journal of Nuclear Materials, 1968. 26(2): p. 137-\&.

39. Snead, L.L. and S.J. Zinkle, Use of beryllium and beryllium oxide in space reactors, in Space Technology and Applications International Forum-Staif 2005, M.S. ElGenk, Editor. 2005. p. 768-775.

40. Zinkle, S.J. and G.P. Pells, Microstructure of Al2O3 and MgAl2O4 irradiated at low temperatures. Journal of Nuclear Materials, 1998. 253: p. 120-132.

41. Hickman, B.S. and D.G. Walker, The effect of neutron irradiaiton on aluminium oxide. Journal of Nuclear Materials, 1966. 18(2): p. 197-205.

42. Snead, L.L., Y. Katoh, and S. Connery, Swelling of SiC at intermediate and high irradiation temperatures. Journal of Nuclear Materials, 2007. 367: p. 677-684.

43. Yano, T. and T. Iseki, Swelling and microstructure of AIN irradiated in a fastreactor. Journal of Nuclear Materials, 1993. 203(3): p. 249-254.

44. Iseki, T., et al., Hardening by point-defects in neutron-irradiated AIN and SiC. Journal of Nuclear Science and Technology, 1993. 30(1): p. 68-77.

45. Snead, L.L., et al., Amorphization of SiC under ion and neutron irradiation. Nuclear Instruments \& Methods in Physics Research Section B-Beam Interactions with Materials and Atoms, 1998. 141(1-4): p. 123-132.

46. Suematsu, H., et al., Point-defect hardening in $\mathrm{MgO} \cdot 3 \mathrm{AL}_{2} \mathrm{O}_{3}$. Journal of the American Ceramic Society, 1992. 75(7): p. 1742-1747.

47. Yang, Y., et al., Microstructure and mechanical properties of proton irradiated zirconium carbide. Journal of Nuclear Materials, 2008. 378(3): p. 341-348.

48. Zinkle, S.J., Hardness and Depth-Dependent Microstructure of Ion-Irradiated Magnesium Aluminate Spinel. Journal of the American Ceramic Society, 1989. 72(8): p. 1343-1351.

49. Hurley, G.F., et al., Structural properties of $\mathrm{MgO}$ and MgAl2O4, after fission neutron irradiation near room temperature. Journal of Nuclear Materials, 1981. 103: p. 761-765.

50. Zinkle, S.J. and B.N. Singh, Microstructure of neutron-irradiated iron before and after tensile deformation. Journal of Nuclear Materials, 2006. 351(1-3): p. 269284.

51. Sikka, V.K. and J. Moteff, Rafting in neutron-irradiated tungsten. Journal of Nuclear Materials, 1973. 46(2): p. 217-219.

52. Eyre, B.L., Transmission Electron-Microscope studies of point-defect clusters in FCC and BCC metals. Journal of Physics F-Metal Physics, 1973. 3(2): p. 422-\&. 


\section{LIST OF TABLES}

Table 1 List of irradiation conditions and corresponding fluences............................. 23

Table 2 Irradiation-induced surface cracking per unit volume in $\mathrm{Ti}_{3} \mathrm{AlC}_{2}, \mathrm{Ti}_{2} \mathrm{AIC}$, and

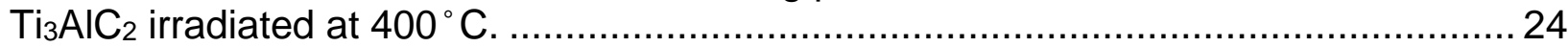

Table 3 Irradiation-induced changes in the prismatic and basal lattice parameters of $\mathrm{Ti}_{3} \mathrm{AlC}_{2}, \mathrm{Ti}_{2} \mathrm{AIC}$, and $\mathrm{Ti}_{3} \mathrm{SiC}_{2}$ after irradiation up to $30 \mathrm{dpa}$ at $400^{\circ} \mathrm{C}$ and at $700^{\circ} \mathrm{C} \ldots \ldots .25$ Table 4 Comparison of experimental differential strain to estimated critical differential strain required for grain boundary cracking ...................................................... 26 


\section{TABLES}

Table 1 List of irradiation conditions and corresponding fluences.

\begin{tabular}{|ccc|}
\hline $\begin{array}{c}\text { Midrange Dose } \\
\text { (dpa) }\end{array}$ & $\begin{array}{c}\text { Fluence } \\
\left(\text { ion } / \mathrm{cm}^{2}\right)\end{array}$ & $\begin{array}{c}\text { Temp. } \\
\left({ }^{\circ} \mathrm{C}\right)\end{array}$ \\
\hline 10 & $2.43 \times 10^{16}$ & 400 \\
10 & $2.43 \times 10^{16}$ & 700 \\
30 & $7.30 \times 10^{16}$ & 400 \\
30 & $7.30 \times 10^{16}$ & 700 \\
\hline
\end{tabular}


Table 2 Irradiation-induced surface cracking per unit volume in $\mathrm{Ti}_{3} \mathrm{AlC}_{2}, \mathrm{Ti}_{2} \mathrm{AIC}$, and $\mathrm{Ti}_{3} \mathrm{AlC}_{2}$ irradiated at $400^{\circ} \mathrm{C}$.

\begin{tabular}{|cc|}
\hline Sample & $\mathrm{S}_{\mathrm{v}}(1 / \mu \mathrm{m})$ \\
\hline $\mathrm{Ti}_{3} \mathrm{AlC}_{2}-10 \mathrm{dpa}-400{ }^{\circ} \mathrm{C}$ & $0.152(9)$ \\
$\mathrm{Ti}_{3} \mathrm{AlC}_{2}-30 \mathrm{dpa}-400{ }^{\circ} \mathrm{C}$ & $0.149(8)$ \\
& \\
& \\
$\mathrm{Ti}{ }_{2} \mathrm{AlC}-10 \mathrm{dpa}-400{ }^{\circ} \mathrm{C}$ & $0.21(1)$ \\
$\mathrm{Ti}_{2} \mathrm{AlC}-30 \mathrm{dpa}-400{ }^{\circ} \mathrm{C}$ & $0.20(1)$ \\
& \\
$\mathrm{Ti}_{3} \mathrm{SiC}_{2}-10 \mathrm{dpa}-400{ }^{\circ} \mathrm{C}$ & 0.0 \\
$\mathrm{Ti}_{3} \mathrm{SiC}_{2}-30 \mathrm{dpa}-400^{\circ} \mathrm{C}$ & 0.0 \\
\hline
\end{tabular}


Table 3 Irradiation-induced changes in the prismatic and basal lattice parameters of $\mathrm{Ti}_{3} \mathrm{AlC}_{2}, \mathrm{Ti}_{2} \mathrm{AIC}$, and $\mathrm{Ti}_{3} \mathrm{SiC}_{2}$ after irradiation up to $30 \mathrm{dpa}$ at $400^{\circ} \mathrm{C}$ and at $700^{\circ} \mathrm{C}$.

\begin{tabular}{|c|c|c|c|c|}
\hline Condition & a-LP $(\AA)$ & $\begin{array}{c}\Delta \mathrm{a}-\mathrm{LP} \\
(\%)\end{array}$ & c-LP $(\AA)$ & $\begin{array}{c}\Delta c-L P \\
(\%)\end{array}$ \\
\hline $\mathrm{Ti}_{3} \mathrm{AlC}_{2}$-Pristine & $3.0735(7)$ & - & $18.54(6)$ & - \\
\hline $\mathrm{Ti}_{3} \mathrm{AlC}_{2}-10 \mathrm{dpa}-400^{\circ} \mathrm{C}$ & $3.068(6)$ & -0.18 & $18.74(7)$ & 1.08 \\
\hline $\mathrm{Ti}_{3} \mathrm{AlC}_{2}-10 \mathrm{dpa}-700^{\circ} \mathrm{C}$ & $3.070(1)$ & -0.11 & $18.60(1)$ & 0.32 \\
\hline $\mathrm{Ti}_{3} \mathrm{AlC}_{2}-30 \mathrm{dpa}-400^{\circ} \mathrm{C}$ & $3.065(5)$ & -0.28 & $18.74(9)$ & 1.08 \\
\hline $\mathrm{Ti}_{3} \mathrm{AlC}_{2}-30 \mathrm{dpa}-700^{\circ} \mathrm{C}$ & $3.076(3)$ & 0.08 & $18.61(3)$ & 0.38 \\
\hline Ti ${ }_{2}$ AlC-Pristine & $3.061(8)$ & - & $13.41(5)$ & - \\
\hline $\mathrm{Ti}_{2} \mathrm{AIC}-30 \mathrm{dpa}-400^{\circ} \mathrm{C}$ & $3.04(1)$ & -0.69 & $13.74(8)$ & 2.46 \\
\hline $\mathrm{Ti}_{2} \mathrm{AIC}-30 \mathrm{dpa}-700^{\circ} \mathrm{C}$ & $3.055(7)$ & -0.20 & $13.38(5)$ & -0.22 \\
\hline $\mathrm{Ti}_{3} \mathrm{SiC}_{2}$-Pristine & $3.059(4)$ & - & $17.65(4)$ & - \\
\hline $\mathrm{Ti}_{3} \mathrm{SiC}_{2}-30 \mathrm{dpa}-400^{\circ} \mathrm{C}$ & $3.069(3)$ & 0.33 & $17.72(6)$ & 0.40 \\
\hline $\mathrm{Ti}_{3} \mathrm{SiC}_{2}-30 \mathrm{dpa}-700^{\circ} \mathrm{C}$ & $3.067(3)$ & 0.26 & $17.61(3)$ & -0.23 \\
\hline
\end{tabular}

Numbers in parentheses represent one standard deviation of the last significant digit. 
Table 4 Comparison of experimental differential strain to estimated critical differential strain required for grain boundary cracking.

\begin{tabular}{|cccc|}
\hline Sample & $\varepsilon$ at $400^{\circ} \mathrm{C}$ & $\varepsilon$ at $700^{\circ} \mathrm{C}$ & $\varepsilon$ critical \\
\hline $\mathrm{Ti}_{3} \mathrm{AlC}_{2}$ & $1.36 \times 10^{-2}$ & $2.96 \times 10^{-3}$ & $3.89 \times 10^{-3}$ \\
$\mathrm{Ti}_{2} \mathrm{AlC}$ & $3.15 \times 10^{-2}$ & $2.77 \times 10^{-4}$ & $5.10 \times 10^{-3}$ \\
$\mathrm{Ti}_{3} \mathrm{SiC}_{2}$ & $6.97 \times 10^{-4}$ & $4.88 \times 10^{-3}$ & $5.14 \times 10^{-3}$ \\
\hline
\end{tabular}




\section{LIST OF FIGURES}

Figure 1 Normalized damage versus depth profiles for $5.8 \mathrm{MeV} \mathrm{Ni}^{4+}$ ion irradiated MAX

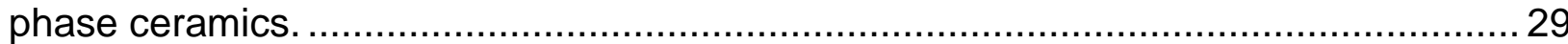

Figure 2 SEM surface imaging on $\mathrm{Ni}$ ion irradiated $\mathrm{Ti}_{3} \mathrm{AlC}_{2}$ for (a) $10 \mathrm{dpa}-400{ }^{\circ} \mathrm{C}$, (b) 10 dpa $-700{ }^{\circ} \mathrm{C}$, (c) $30 \mathrm{dpa}-400{ }^{\circ} \mathrm{C}$, and (d) $30 \mathrm{dpa}-700^{\circ} \mathrm{C}$ irradiation conditions............. 30 Figure 3 SEM surface imaging on Ni ion irradiated Ti2AIC for (a) $10 \mathrm{dpa}-400{ }^{\circ} \mathrm{C}$, (b) 10 dpa-700 ${ }^{\circ} \mathrm{C}$, (c) $30 \mathrm{dpa}-400^{\circ} \mathrm{C}$, and (d) $30 \mathrm{dpa}-700{ }^{\circ} \mathrm{C}$ irradiation conditions................ 31 Figure $4 \mathrm{SEM}$ surface imaging on $\mathrm{Ni}$ ion irradiated $\mathrm{Ti}_{3} \mathrm{SiC}_{2}$ for (a) $10 \mathrm{dpa}-400{ }^{\circ} \mathrm{C}$, (b) 10 dpa-700 ${ }^{\circ} \mathrm{C}$, (c) $30 \mathrm{dpa}-400{ }^{\circ} \mathrm{C}$, and (d) $30 \mathrm{dpa}-700{ }^{\circ} \mathrm{C}$ irradiation conditions............... 32 Figure 5 GXRD data of $\mathrm{Ti}_{3} \mathrm{AIC}_{2}$ irradiated to a midrange dose of $10 \mathrm{dpa}$ using $5.8 \mathrm{MeV}$ $\mathrm{Ni}$ ions at (a) $10 \mathrm{dpa}-400{ }^{\circ} \mathrm{C}$, (b) $10 \mathrm{dpa}-700^{\circ} \mathrm{C}$, (d) $30 \mathrm{dpa}-400{ }^{\circ} \mathrm{C}$, (e) $30 \mathrm{dpa}-700^{\circ} \mathrm{C}$, and (c\&f) Pristine $\mathrm{Ti}_{3} \mathrm{AlC}_{2}$. Black data points, solid red lines, and solid green lines represent the observed data, calculated model, and the difference between the two respectively.

Figure 6 GXRD data of Ti $2 \mathrm{AIC}$ irradiated to a midrange dose of $30 \mathrm{dpa}$ using $5.8 \mathrm{MeV}$ $\mathrm{Ni}$ ions at (a) $30 \mathrm{dpa}-400^{\circ} \mathrm{C}$, (b) $30 \mathrm{dpa}-700^{\circ} \mathrm{C}$, and (c) Pristine Ti $2 \mathrm{AlC}$. Black data points, solid red lines, and solid green lines represent the observed data, calculated model, and the difference between the two respectively.

Figure $7 \mathrm{GXRD}$ data of $\mathrm{Ti}_{3} \mathrm{SiC}_{2}$ irradiated to a midrange dose of $30 \mathrm{dpa}$ using $5.8 \mathrm{MeV}$ $\mathrm{Ni}$ ions at (a) $30 \mathrm{dpa}-400^{\circ} \mathrm{C}$, (b) $30 \mathrm{dpa}-700^{\circ} \mathrm{C}$, and (c) Pristine $\mathrm{Ti}_{3} \mathrm{SiC}_{2}$. Black data points, solid red lines, and solid green lines represent the observed data, calculated model, and the difference between the two respectively.

Figure 8 Temperature dependent relative lattice parameter shifts at 30 dpa midrange dose for (a) C-LP and (b) a-LP. 36

Figure 9 Normalized hardness dose dependence in irradiated $\mathrm{Ti}_{3} \mathrm{AlC}_{2}, \mathrm{Ti}_{2} \mathrm{AIC}$, and $\mathrm{Ti}_{3} \mathrm{SiC}_{2}$ by $5.8 \mathrm{MeV} \mathrm{Ni}$ ions at (a) $400{ }^{\circ} \mathrm{C}$ and (b) $700{ }^{\circ} \mathrm{C}$. 37 Figure 10 Normalized hardness temperature dependence in irradiated $\mathrm{Ti}_{3} \mathrm{AlC}_{2}, \mathrm{Ti}_{2} \mathrm{AIC}$, and $\mathrm{Ti}_{3} \mathrm{SiC}_{2}$ by $5.8 \mathrm{MeV} \mathrm{Ni}$ ions at midrange doses of (a) $10 \mathrm{dpa}$ and (b) $30 \mathrm{dpa}$..........38 Figure 11 Normalized elastic modulus dose dependence in irradiated $\mathrm{Ti}_{3} \mathrm{AlC}_{2}, \mathrm{Ti}_{2} \mathrm{AlC}$, and $\mathrm{Ti}_{3} \mathrm{SiC}_{2}$ by $5.8 \mathrm{MeV} \mathrm{Ni}$ ions at (a) $400{ }^{\circ} \mathrm{C}$ and (b) $700{ }^{\circ} \mathrm{C}$. 39

Figure 12 Normalized elastic modulus temperature dependence in irradiated $\mathrm{Ti}_{3} \mathrm{AlC}_{2}$, $\mathrm{Ti}_{2} \mathrm{AlC}$, and $\mathrm{Ti}_{3} \mathrm{SiC}_{2}$ by $5.8 \mathrm{MeV} \mathrm{Ni}$ ions at midrange doses of (a) $10 \mathrm{dpa}$ and (b) $30 \mathrm{dpa}$.

Figure 13 SEM morphology of indents on (a) $10 \mathrm{dpa}-400^{\circ} \mathrm{C}$, and (b) $10 \mathrm{dpa}-700{ }^{\circ} \mathrm{C} \mathrm{Ni}$ ion irradiated $\mathrm{Ti}_{3} \mathrm{AlC}_{2}$.

Figure $14 \mathrm{SEM}$ morphology of indents on (a) $10 \mathrm{dpa}-400^{\circ} \mathrm{C}$, and (b) $10 \mathrm{dpa}-700{ }^{\circ} \mathrm{C} \mathrm{Ni}$ ion irradiated $\mathrm{Ti}_{2} \mathrm{AlC}$.

Figure 15 SEM morphology of indents on (a) $10 \mathrm{dpa}-400^{\circ} \mathrm{C}$, and (b) $10 \mathrm{dpa}-700{ }^{\circ} \mathrm{C} \mathrm{Ni}$

ion irradiated $\mathrm{Ti}_{3} \mathrm{SiC}_{2}$.

Figure 16 Cross-sectional TEM micrograph of the full $\mathrm{Ti}_{3} \mathrm{AlC}_{2}$ foil irradiated to $30 \mathrm{dpa}$ at $400{ }^{\circ} \mathrm{C}$ using $5.8 \mathrm{MeV} \mathrm{Ni}$ ions, with ion direction denoted by the green arrow. The dashed white line denotes the transition depth between the ion irradiated area and the non-irradiated bulk. Region 1 denotes the selected area for ion radiation damage characterization and Region 2 denotes the selected area for pristine crystal 
characterization. SAED pattern for the pristine crystal can be seen in the upper righthand corner.

Figure 17 High magnification bright field and dark field cross-sectional TEM micrographs of pristine $\mathrm{Ti}_{3} \mathrm{AlC}_{2}$ (region 2). The basal and prism diffraction vector directions are indicated by 0001 and 1100 respectively. Note that FIB samplepreparation induced damage is negligible.

Figure 18 High magnification bright field and dark field cross-sectional TEM micrographs of $5.8 \mathrm{MeV} \mathrm{Ni}$ ions irradiated $\mathrm{Ti}_{3} \mathrm{AlC}_{2}$ to a midrange dose of $30 \mathrm{dpa}$ at a temperature of $400{ }^{\circ} \mathrm{C}$. The basal and prism diffraction vector directions are indicated by 0001 and 1100 respectively.

Figure 19 High magnification bright field and dark fieldcross-sectional TEM micrographs of $5.8 \mathrm{MeV} \mathrm{Ni}$ ions irradiated $\mathrm{Ti}_{3} \mathrm{AlC}_{2}$ to a midrange dose of $30 \mathrm{dpa}$ at a temperature of $700{ }^{\circ} \mathrm{C}$. The diffraction vectors are indicated by 0001 and 1100 respectively. The red marking show the estimated stacking sequence of small defects with respect to the basal plane.

Figure 20 High magnification bright field and dark field cross-sectional TEM micrographs of $5.8 \mathrm{MeV} \mathrm{Ni}$ ions irradiated $\mathrm{Ti}_{3} \mathrm{SiC}_{2}$ to a midrange dose of $30 \mathrm{dpa}$ at a temperature of $700{ }^{\circ} \mathrm{C}$. The diffraction vectors are indicated by 0001 and 0110 respectively.

Figure 21 Volumetric swelling regimes for irradiated $\mathrm{Al}_{2} \mathrm{O}_{3}[40]$

Figure 22 Comprehensive plot of (a) c lattice parameter swelling and (b) a lattice parameter swelling as a function of irradiation temperature for ion irradiated $\mathrm{Ti}_{3} \mathrm{AlC}_{2}$, $\mathrm{Ti}_{2} \mathrm{AlC}$, and $\mathrm{Ti}_{3} \mathrm{SiC}_{2}$. Empty symbols represent the current results, filled symbols represent previous results from literature, and lines represent fits to combined data [14, $16,20]$. 50

Figure 23 Comprehensive plot of fitted total volumetric swelling as a function of irradiation temperature for irradiated $\mathrm{Ti}_{3} \mathrm{AlC}_{2}, \mathrm{Ti}_{2} \mathrm{AIC}, \mathrm{Ti}_{3} \mathrm{SiC}_{2}, \mathrm{Al}_{2} \mathrm{O}_{3}$, and $\mathrm{SiC}[14,16,20$, $40,42]$ 
FIGURES

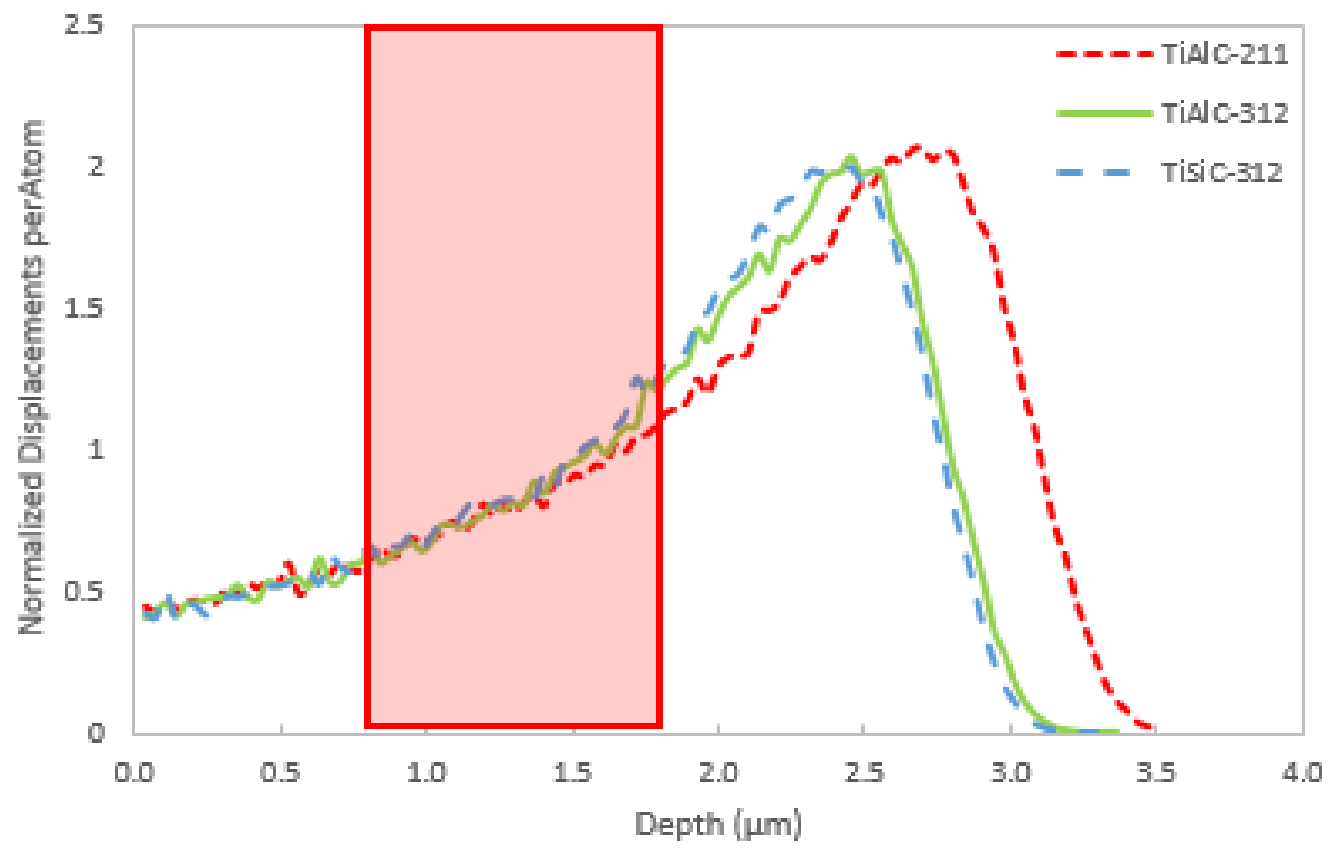

Figure 1 Normalized damage versus depth profiles for $5.8 \mathrm{MeV} \mathrm{Ni}^{4+}$ ion irradiated MAX phase ceramics. 


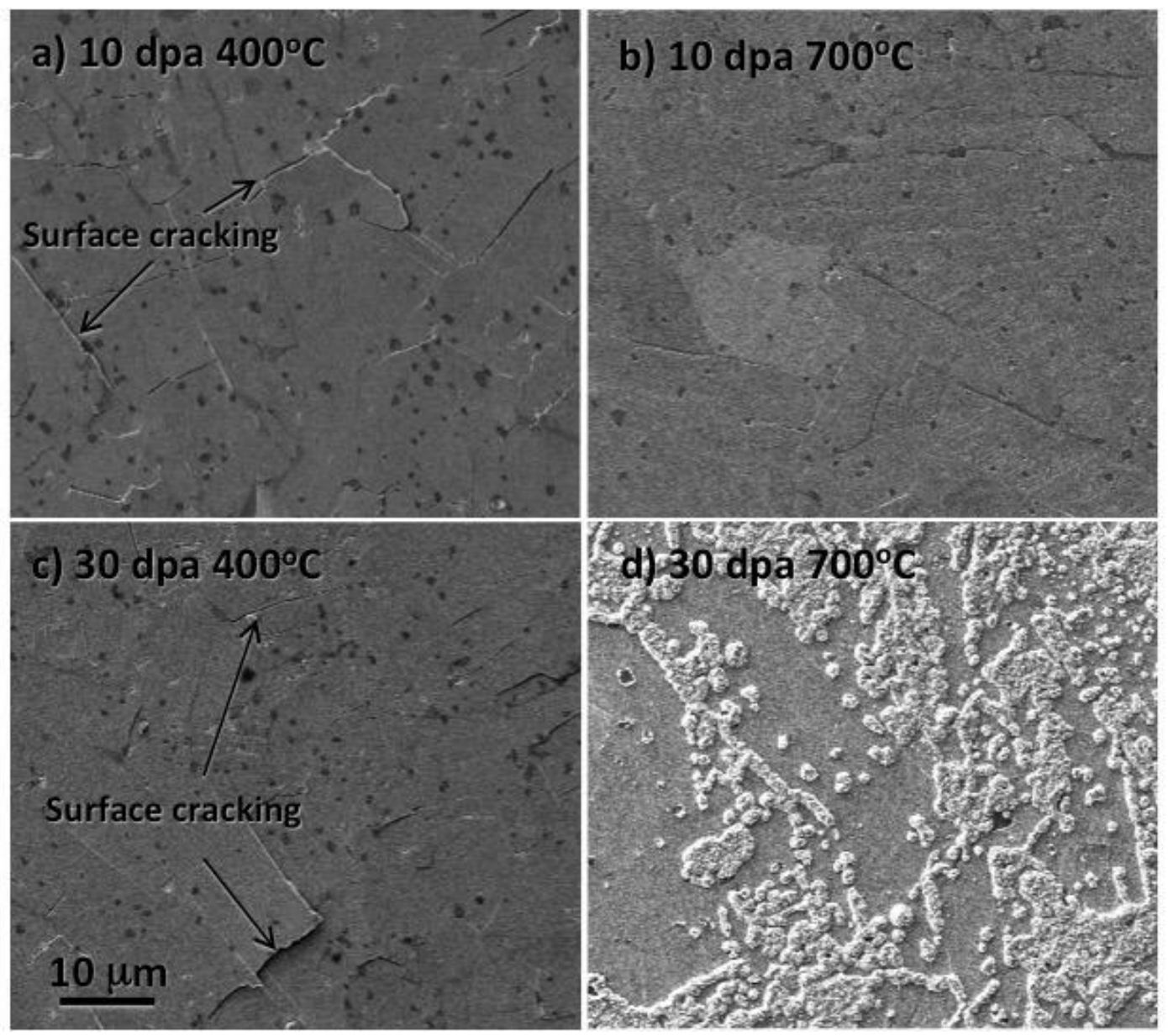

Figure 2 SEM surface imaging on $\mathrm{Ni}$ ion irradiated $\mathrm{Ti}_{3} \mathrm{AlC}_{2}$ for (a) $10 \mathrm{dpa}-400{ }^{\circ} \mathrm{C}$, (b) 10 dpa $-700{ }^{\circ} \mathrm{C}$, (c) $30 \mathrm{dpa}-400{ }^{\circ} \mathrm{C}$, and (d) $30 \mathrm{dpa}-700^{\circ} \mathrm{C}$ irradiation conditions. 


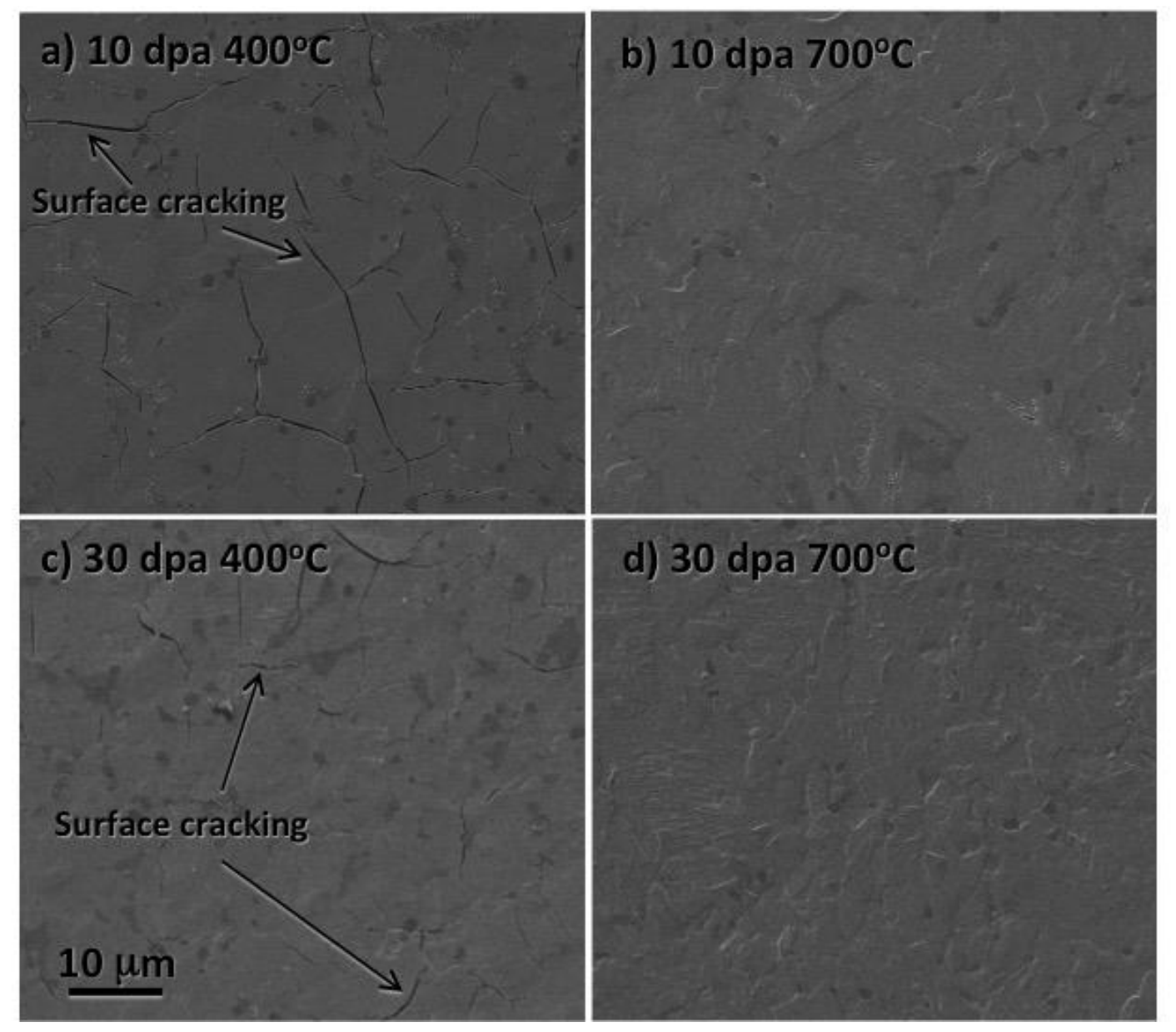

Figure $3 \mathrm{SEM}$ surface imaging on Ni ion irradiated Ti2 $\mathrm{AIC}$ for (a) $10 \mathrm{dpa}-400^{\circ} \mathrm{C}$, (b) 10 dpa- $700{ }^{\circ} \mathrm{C}$, (c) $30 \mathrm{dpa}-400^{\circ} \mathrm{C}$, and (d) $30 \mathrm{dpa}-700^{\circ} \mathrm{C}$ irradiation conditions. 


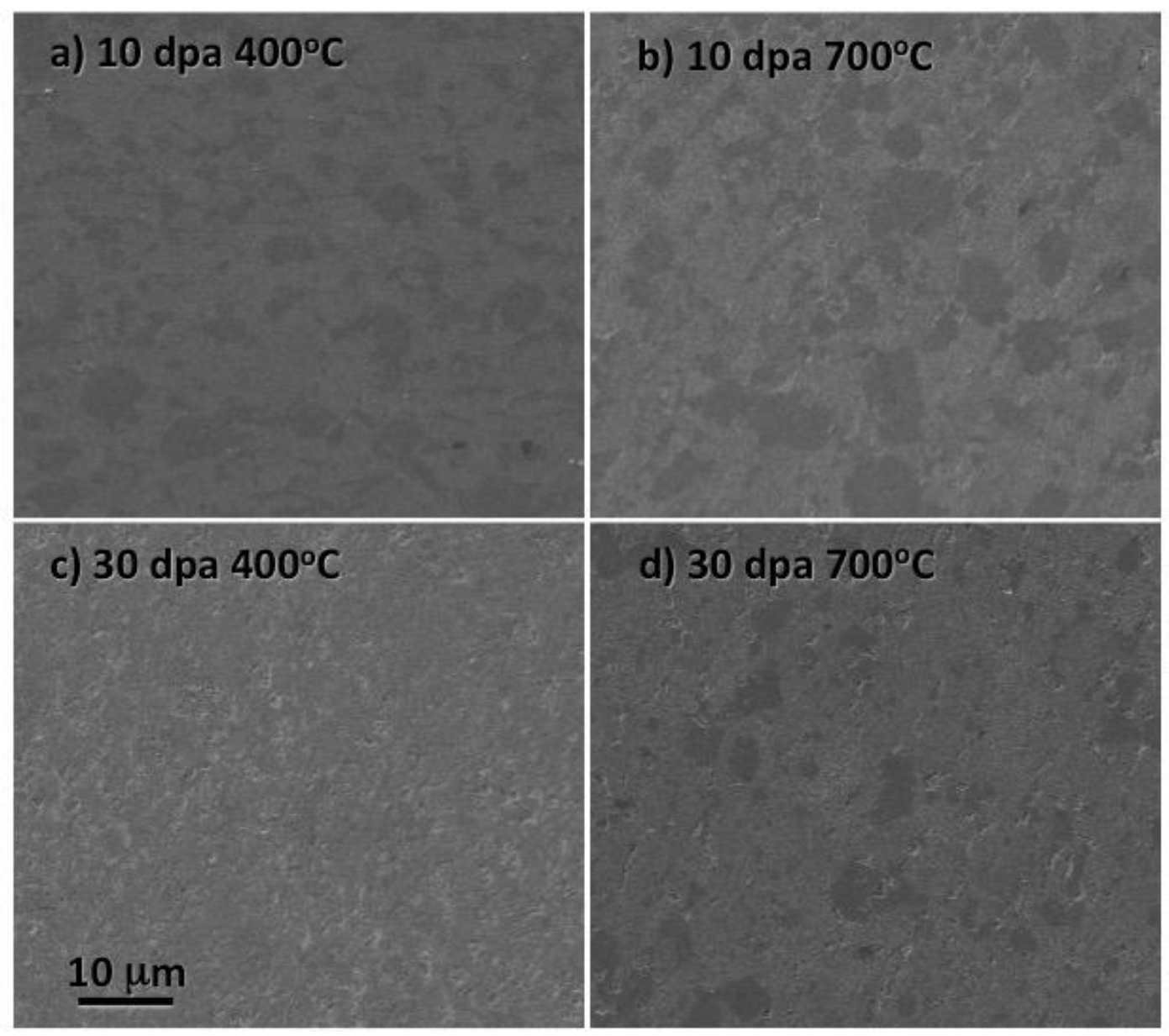

Figure 4 SEM surface imaging on $\mathrm{Ni}$ ion irradiated $\mathrm{Ti}_{3} \mathrm{SiC}_{2}$ for (a) $10 \mathrm{dpa}-400{ }^{\circ} \mathrm{C}$, (b) 10 dpa-700 ${ }^{\circ} \mathrm{C}$, (c) $30 \mathrm{dpa}-400{ }^{\circ} \mathrm{C}$, and (d) $30 \mathrm{dpa}-700^{\circ} \mathrm{C}$ irradiation conditions. 
$\mathrm{Ti}_{3} \mathrm{AlC}_{2}$

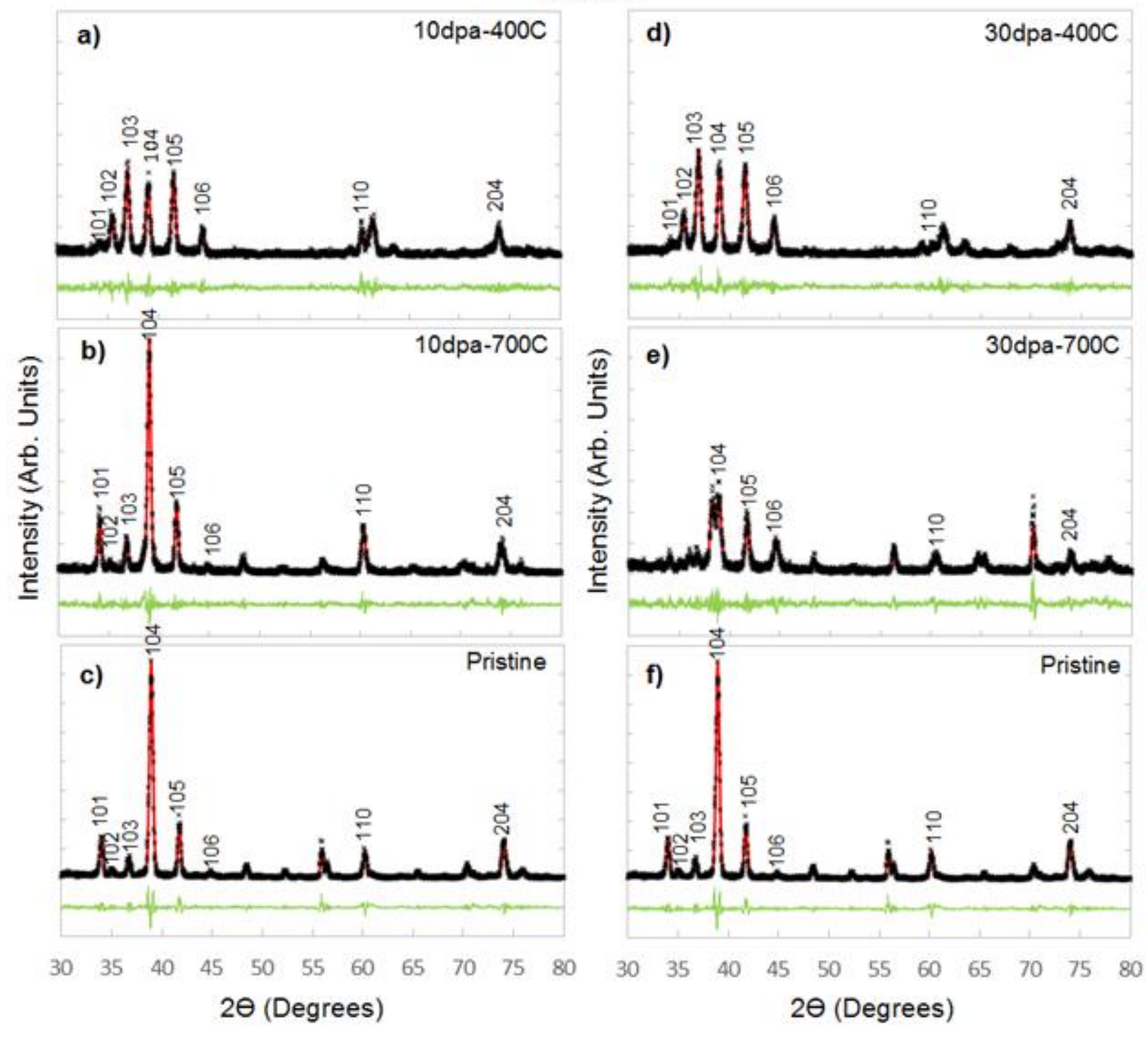

Figure $5 \mathrm{GXRD}$ data of $\mathrm{Ti}_{3} \mathrm{AlC}_{2}$ irradiated to a midrange dose of $10 \mathrm{dpa}$ using $5.8 \mathrm{MeV}$ $\mathrm{Ni}$ ions at (a) $10 \mathrm{dpa}-400{ }^{\circ} \mathrm{C}$, (b) $10 \mathrm{dpa}-700^{\circ} \mathrm{C}$, (d) $30 \mathrm{dpa}-400{ }^{\circ} \mathrm{C}$, (e) $30 \mathrm{dpa}-700^{\circ} \mathrm{C}$, and (c\&f) Pristine $\mathrm{Ti}_{3} \mathrm{AlC}_{2}$. Black data points, solid red lines, and solid green lines represent the observed data, calculated model, and the difference between the two respectively. 

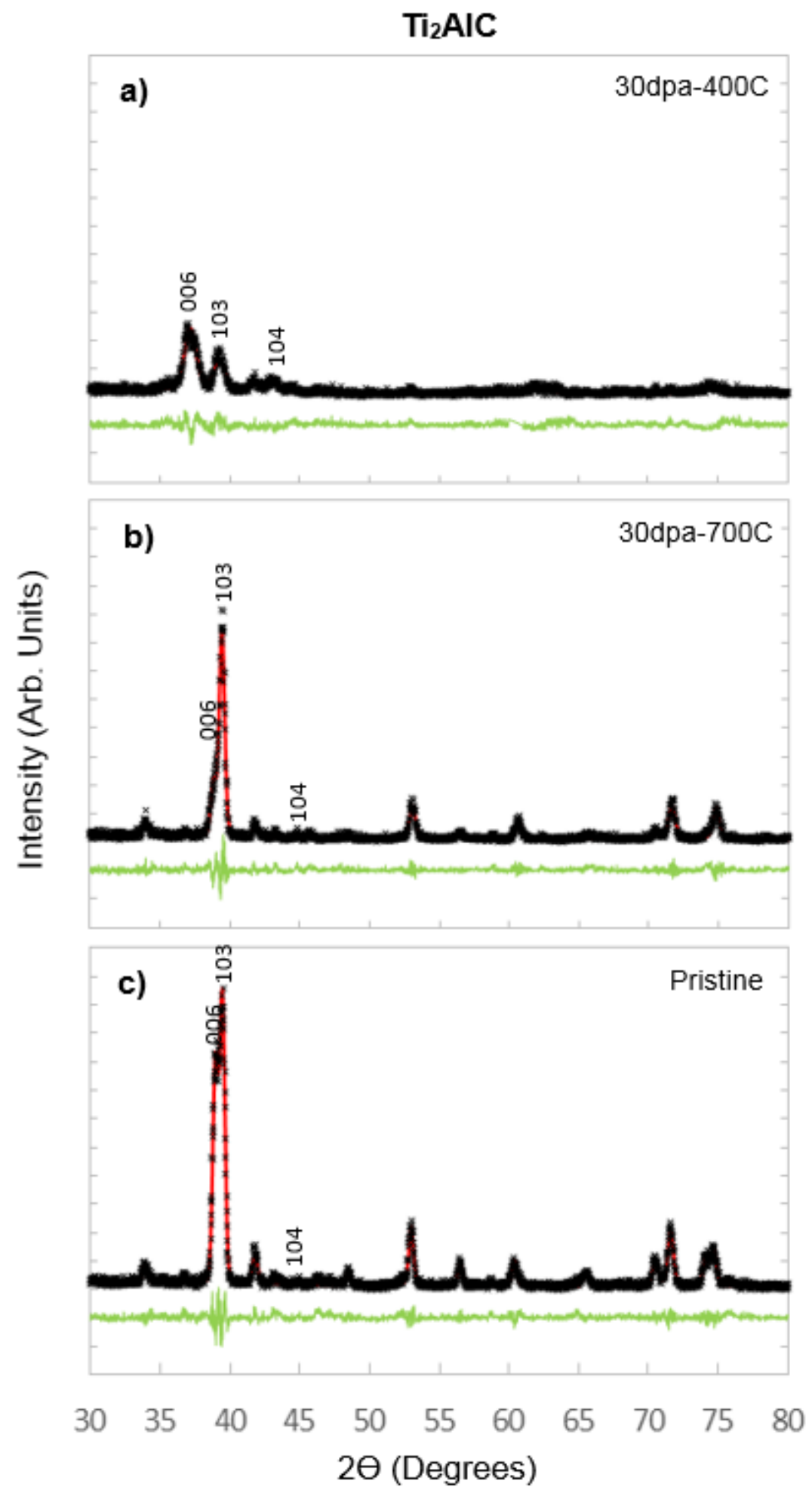

Figure 6 GXRD data of Ti $2 \mathrm{AlC}$ irradiated to a midrange dose of $30 \mathrm{dpa}$ using $5.8 \mathrm{MeV}$ $\mathrm{Ni}$ ions at (a) $30 \mathrm{dpa}-400^{\circ} \mathrm{C}$, (b) $30 \mathrm{dpa}-700^{\circ} \mathrm{C}$, and (c) Pristine Ti2AlC. Black data points, solid red lines, and solid green lines represent the observed data, calculated model, and the difference between the two respectively. 
$\mathrm{Ti}_{3} \mathrm{SiC}_{2}$

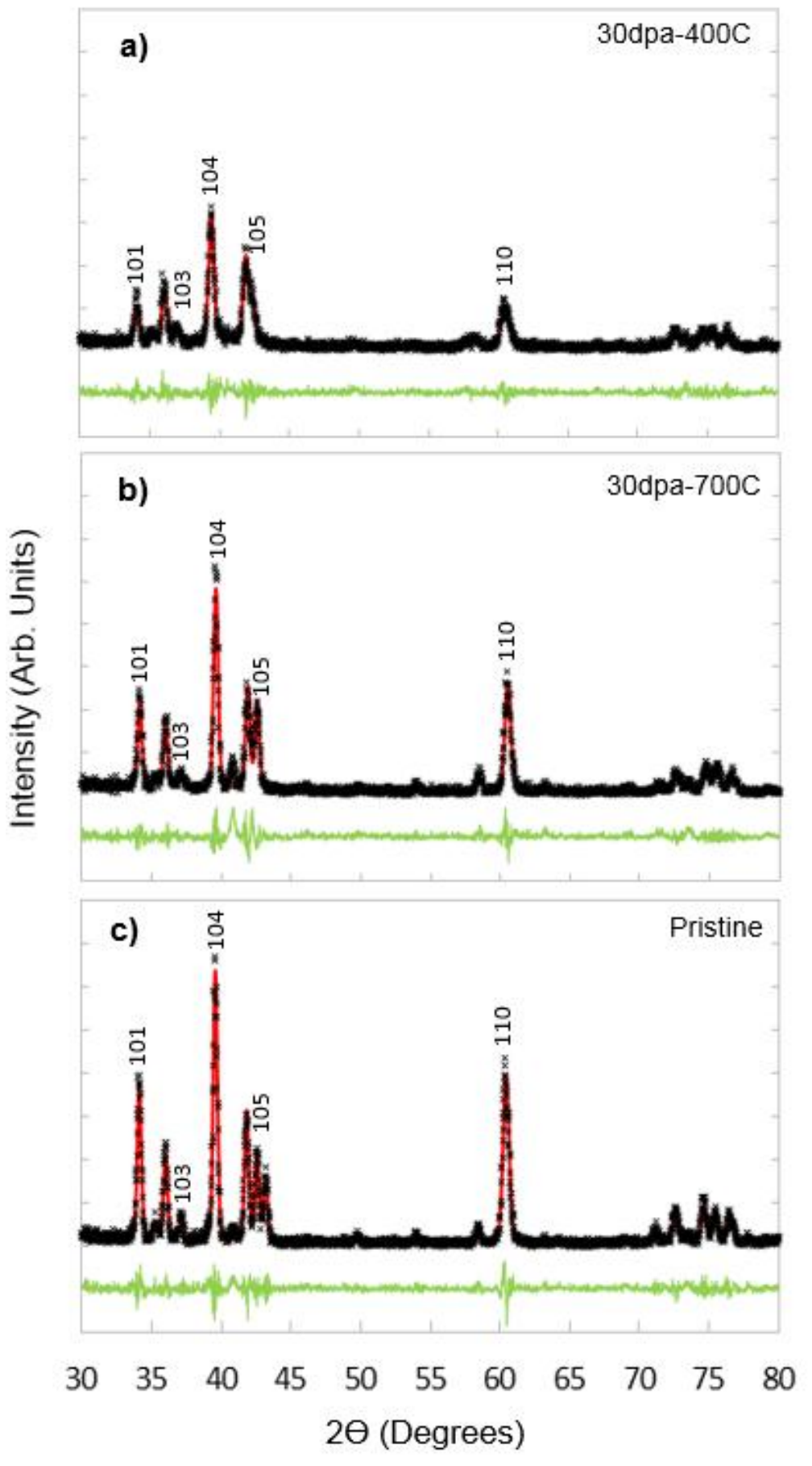

Figure $7 \mathrm{GXRD}$ data of $\mathrm{Ti}_{3} \mathrm{SiC}_{2}$ irradiated to a midrange dose of $30 \mathrm{dpa}$ using $5.8 \mathrm{MeV}$ $\mathrm{Ni}$ ions at (a) $30 \mathrm{dpa}-400^{\circ} \mathrm{C}$, (b) $30 \mathrm{dpa}-700^{\circ} \mathrm{C}$, and (c) Pristine $\mathrm{Ti}_{3} \mathrm{SiC}_{2}$. Black data points, solid red lines, and solid green lines represent the observed data, calculated model, and the difference between the two respectively. 

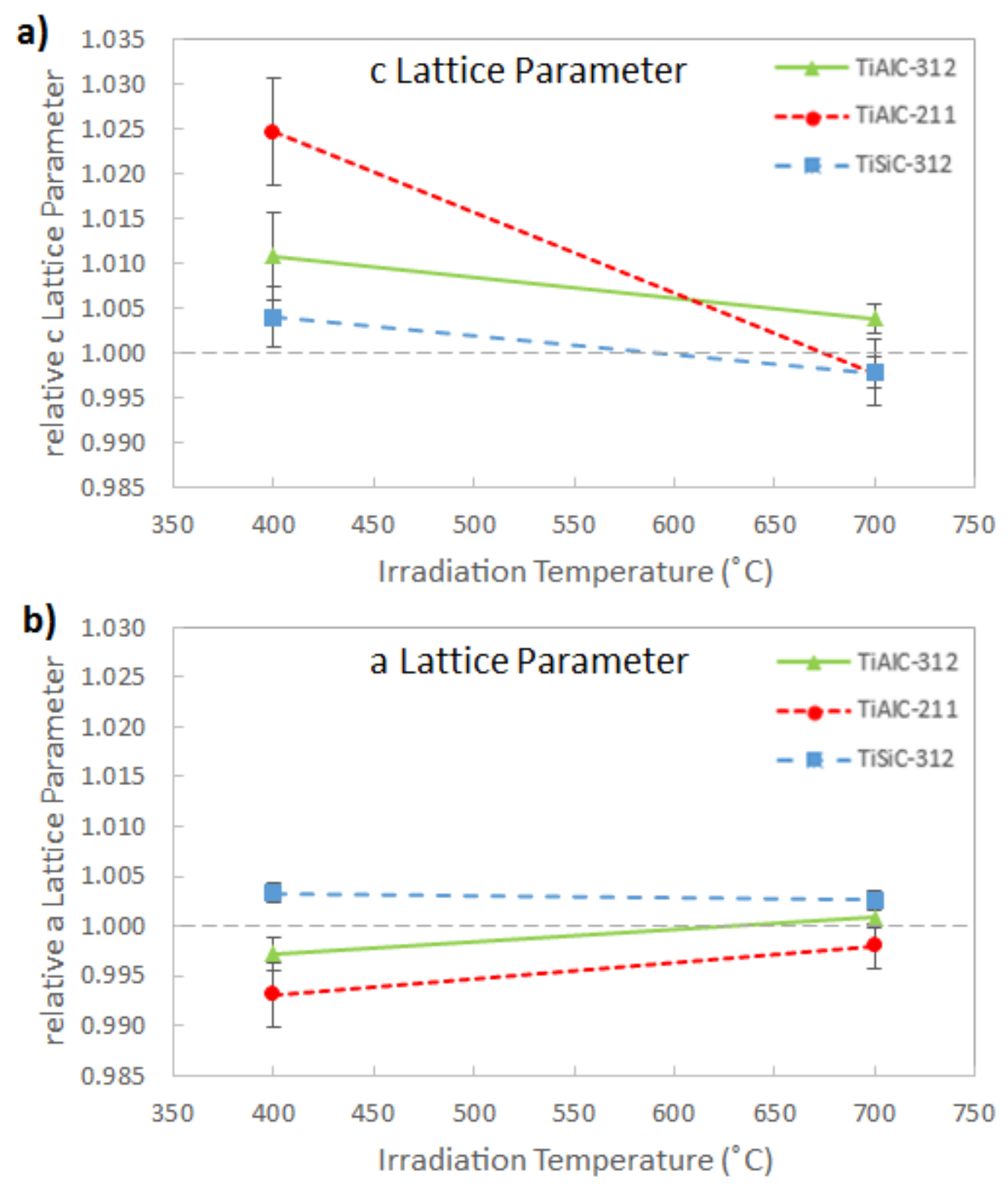

Figure 8 Temperature dependent relative lattice parameter shifts at 30 dpa midrange dose for (a) C-LP and (b) a-LP. 

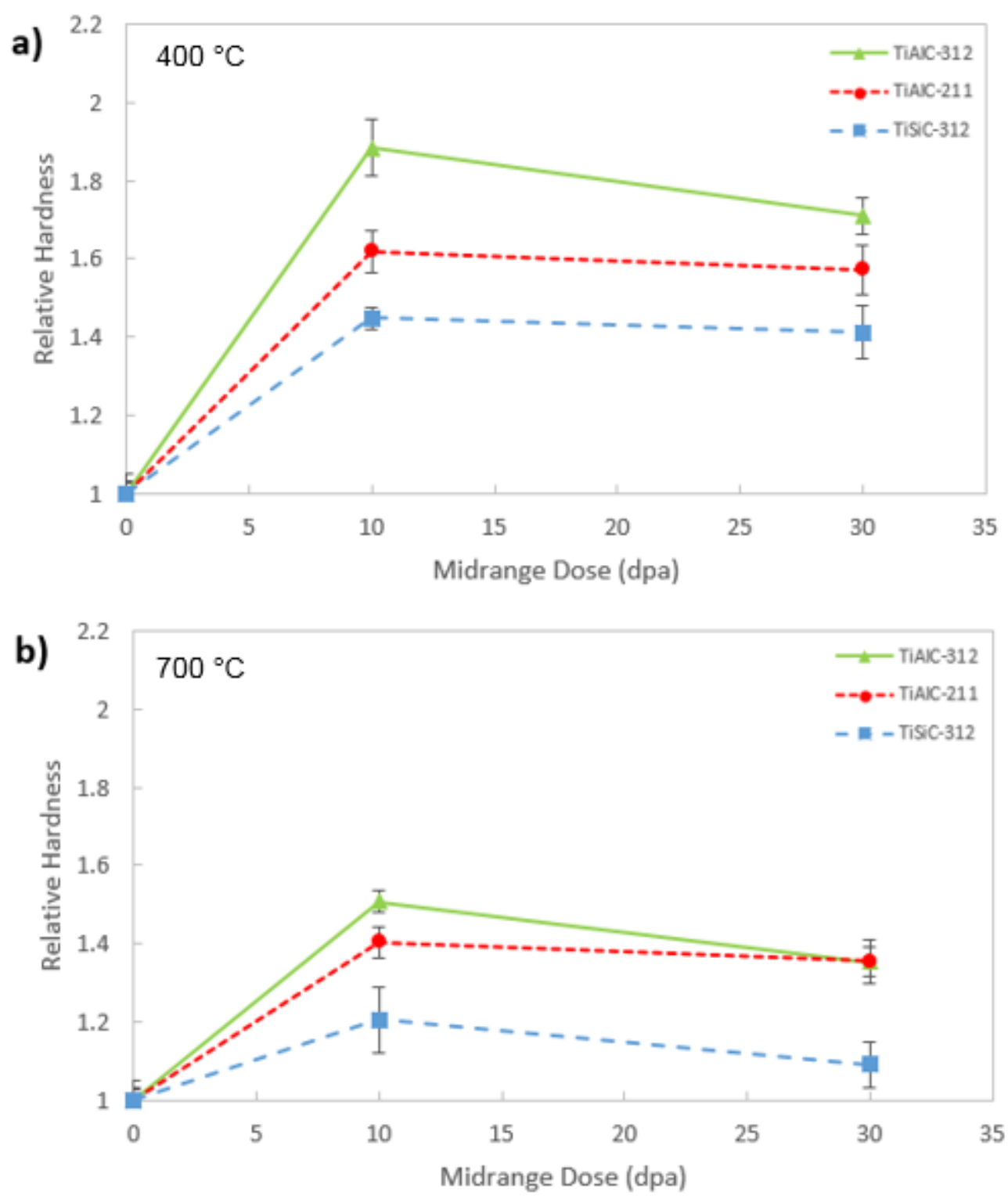

Figure 9 Normalized hardness dose dependence in irradiated $\mathrm{Ti}_{3} \mathrm{AlC}_{2}, \mathrm{Ti}_{2} \mathrm{AIC}$, and $\mathrm{Ti}_{3} \mathrm{SiC}_{2}$ by $5.8 \mathrm{MeV} \mathrm{Ni}$ ions at (a) $400{ }^{\circ} \mathrm{C}$ and (b) $700{ }^{\circ} \mathrm{C}$. 

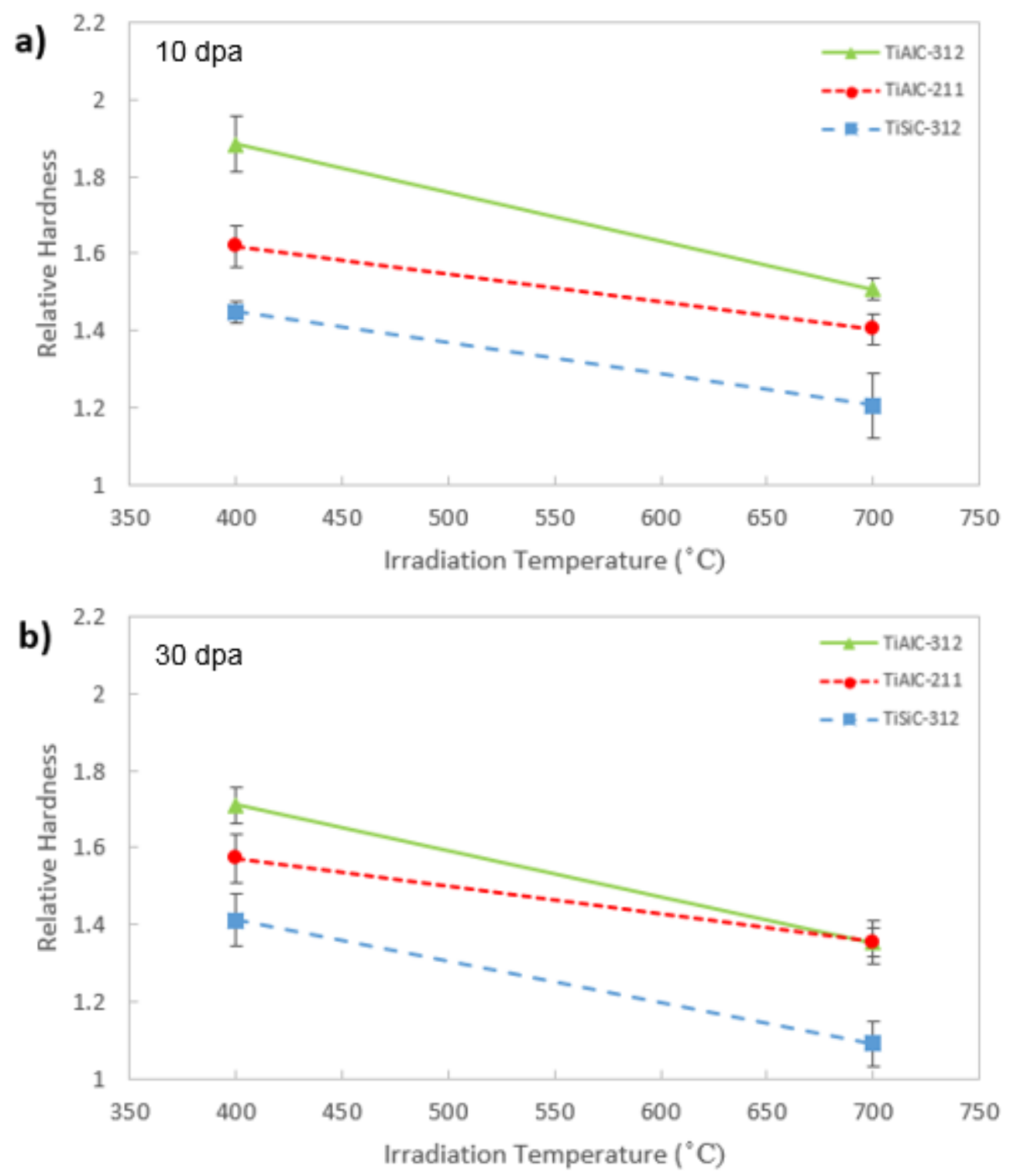

Figure 10 Normalized hardness temperature dependence in irradiated $\mathrm{Ti}_{3} \mathrm{AlC}_{2}, \mathrm{Ti}_{2} \mathrm{AlC}$, and $\mathrm{Ti}_{3} \mathrm{SiC}_{2}$ by $5.8 \mathrm{MeV} \mathrm{Ni}$ ions at midrange doses of (a) $10 \mathrm{dpa}$ and (b) $30 \mathrm{dpa}$. 

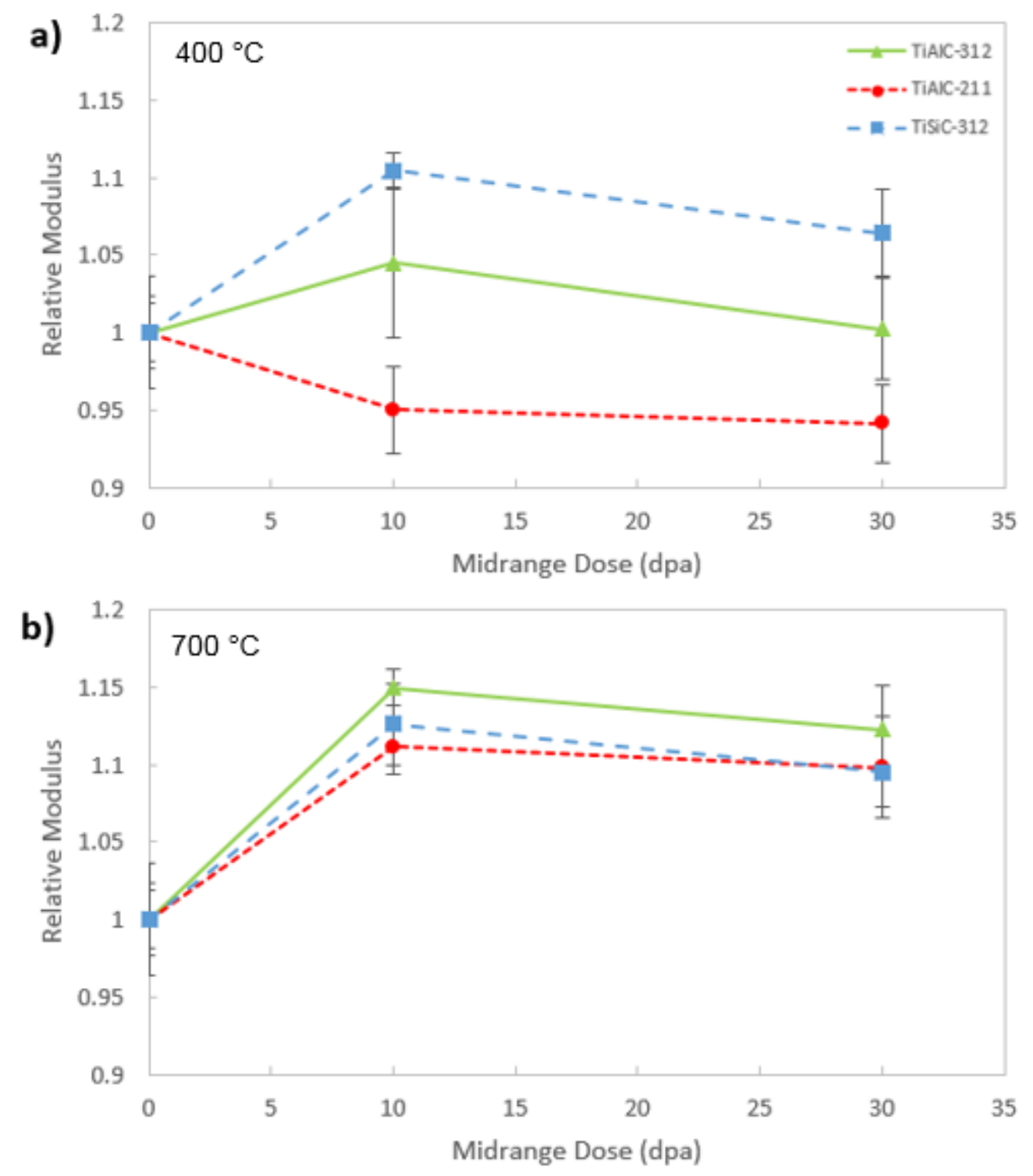

Figure 11 Normalized elastic modulus dose dependence in irradiated $\mathrm{Ti}_{3} \mathrm{AlC}_{2}, \mathrm{Ti}_{2} \mathrm{AIC}$, and $\mathrm{Ti}_{3} \mathrm{SiC}_{2}$ by $5.8 \mathrm{MeV} \mathrm{Ni}$ ions at (a) $400{ }^{\circ} \mathrm{C}$ and (b) $700{ }^{\circ} \mathrm{C}$. 

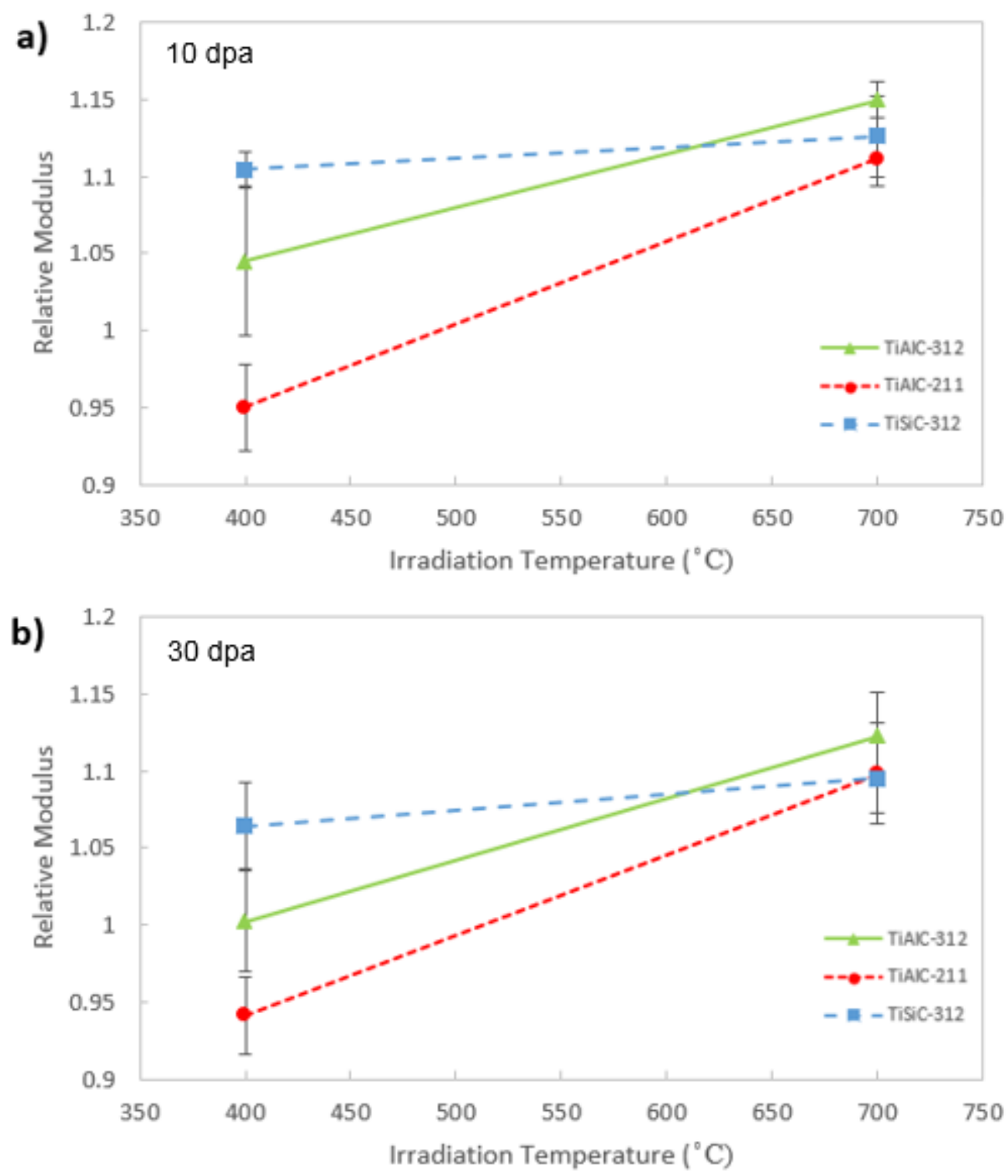

Figure 12 Normalized elastic modulus temperature dependence in irradiated $\mathrm{Ti}_{3} \mathrm{AlC}_{2}$, $\mathrm{Ti}_{2} \mathrm{AlC}$, and $\mathrm{Ti}_{3} \mathrm{SiC}_{2}$ by $5.8 \mathrm{MeV} \mathrm{Ni}$ ions at midrange doses of (a) $10 \mathrm{dpa}$ and (b) $30 \mathrm{dpa}$. 


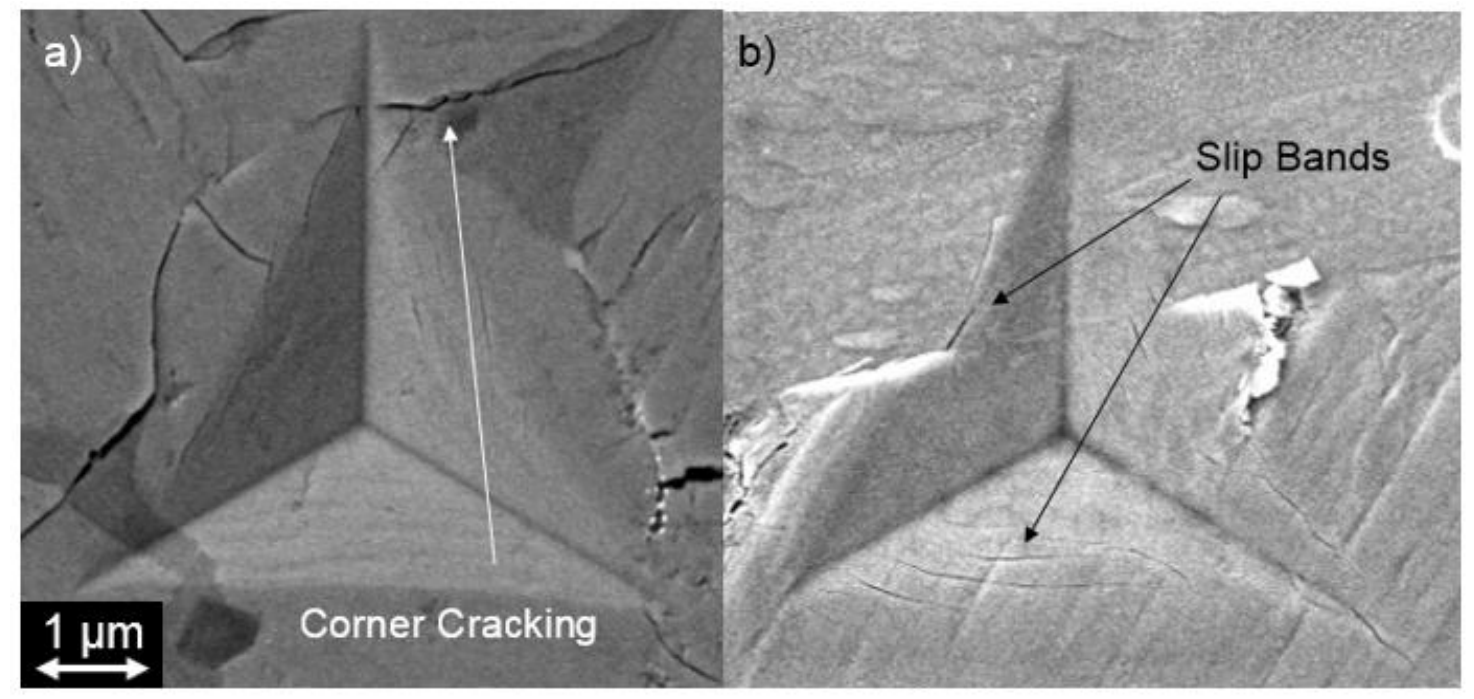

Figure $13 \mathrm{SEM}$ morphology of indents on (a) $10 \mathrm{dpa}-400{ }^{\circ} \mathrm{C}$, and (b) $10 \mathrm{dpa}-700{ }^{\circ} \mathrm{C} \mathrm{Ni}$ ion irradiated $\mathrm{Ti}_{3} \mathrm{AlC}_{2}$.

$1 \mu \mathrm{m}$ 


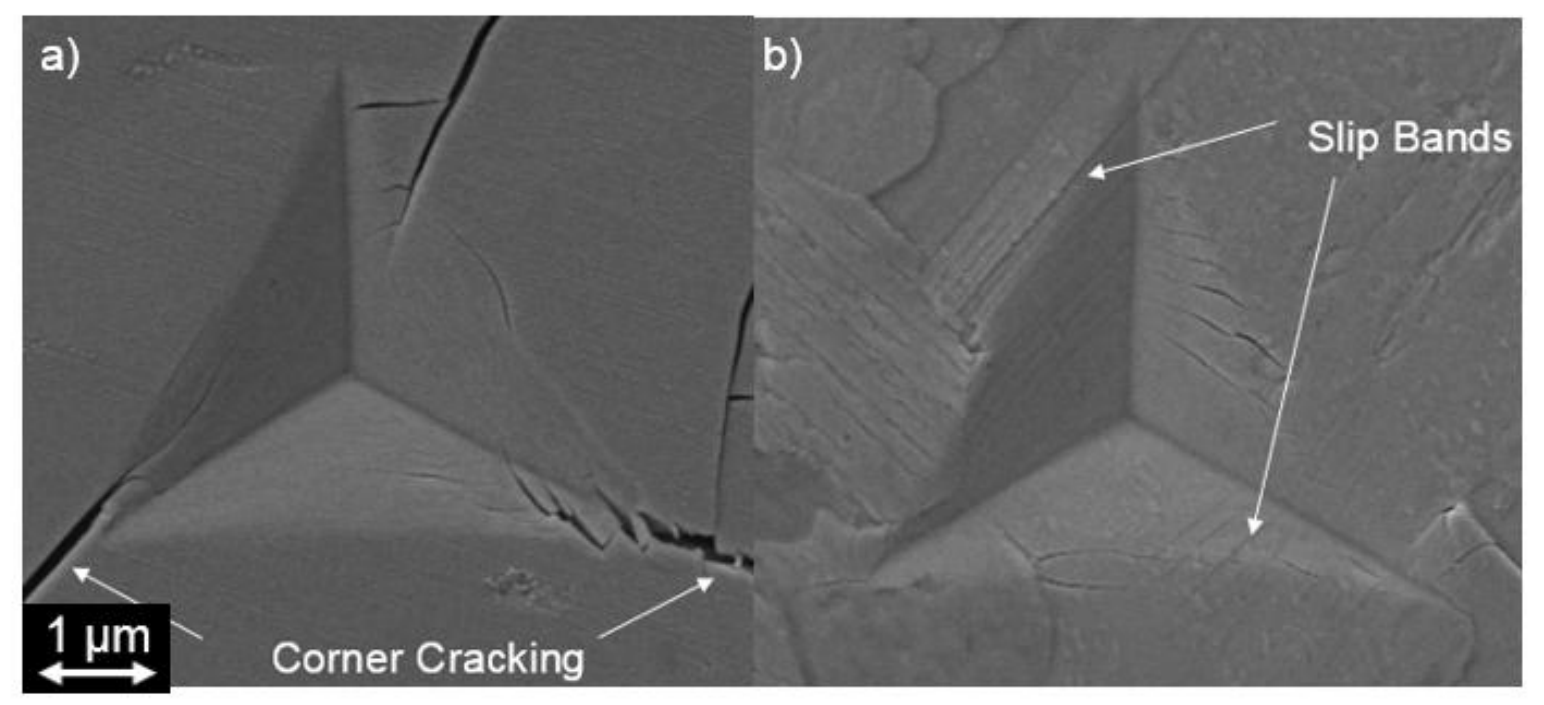

Figure 14 SEM morphology of indents on (a) $10 \mathrm{dpa}-400^{\circ} \mathrm{C}$, and (b) $10 \mathrm{dpa}-700{ }^{\circ} \mathrm{C} \mathrm{Ni}$ ion irradiated $\mathrm{Ti}_{2} \mathrm{AlC}$. 


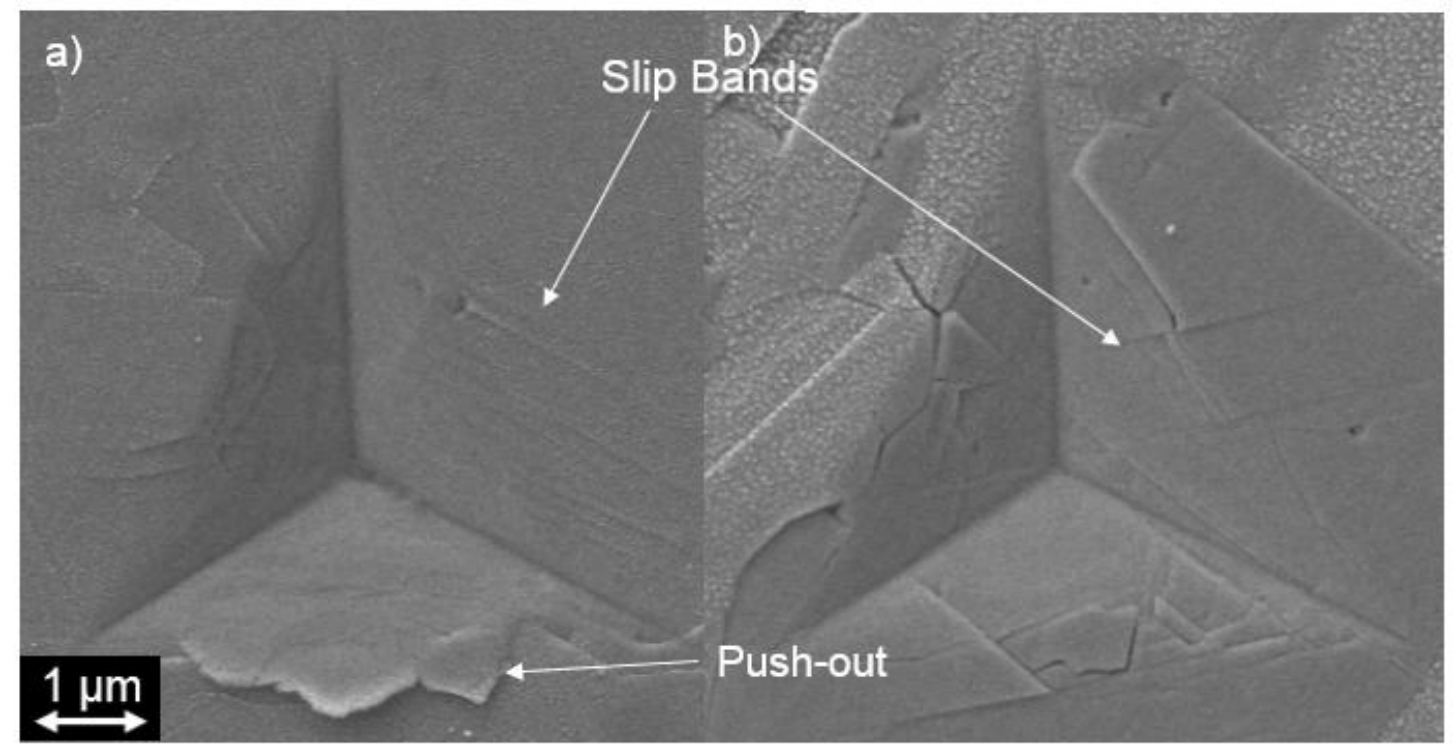

Figure 15 SEM morphology of indents on (a) $10 \mathrm{dpa}-400^{\circ} \mathrm{C}$, and (b) $10 \mathrm{dpa}-700^{\circ} \mathrm{C} \mathrm{Ni}$ ion irradiated $\mathrm{Ti}_{3} \mathrm{SiC}_{2}$. 


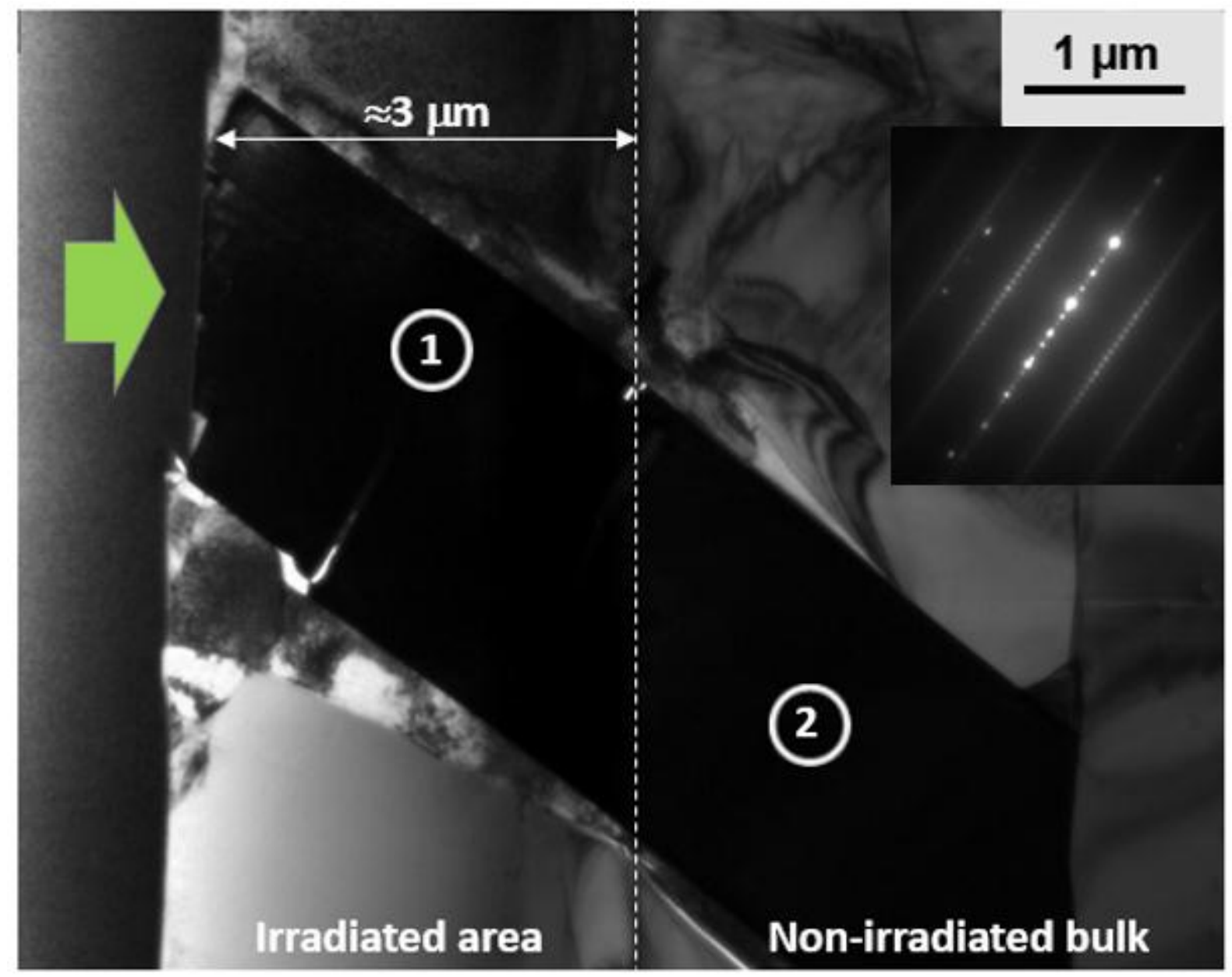

Figure 16 Cross-sectional TEM micrograph of the full $\mathrm{Ti}_{3} \mathrm{AlC}_{2}$ foil irradiated to $30 \mathrm{dpa}$ at $400{ }^{\circ} \mathrm{C}$ using 5.8 MeV Ni ions, with ion direction denoted by the green arrow. The dashed white line denotes the transition depth between the ion irradiated area and the non-irradiated bulk. Region 1 denotes the selected area for ion radiation damage characterization and Region 2 denotes the selected area for pristine crystal characterization. SAED pattern for the pristine crystal can be seen in the upper righthand corner. 


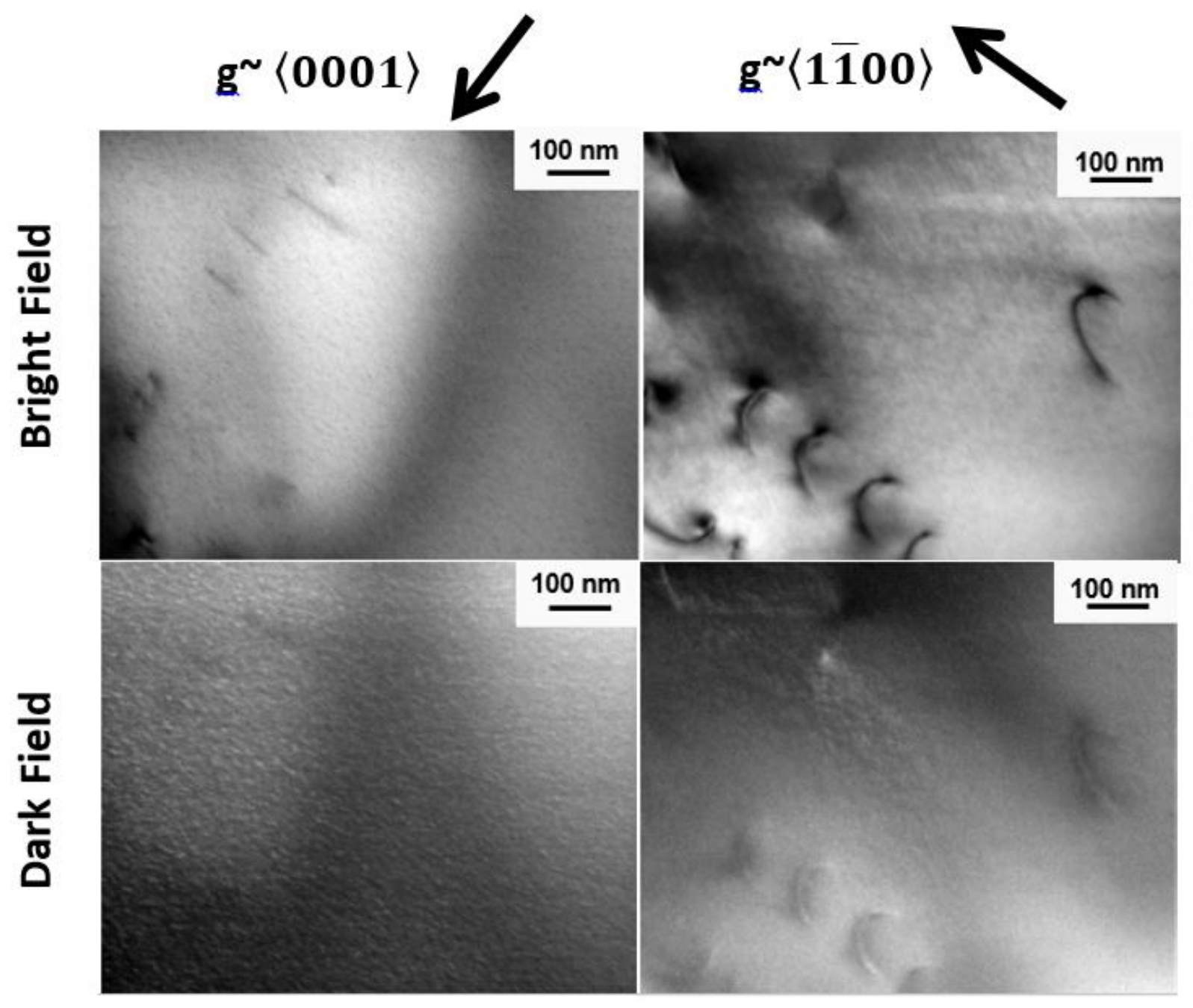

Figure 17 High magnification bright field and dark field cross-sectional TEM micrographs of pristine $\mathrm{Ti}_{3} \mathrm{AlC}_{2}$ (region 2). The basal and prism diffraction vector directions are indicated by $\langle 0001\rangle$ and $\langle 1 \overline{1} 00\rangle$ respectively. Note that FIB samplepreparation induced damage is negligible. 


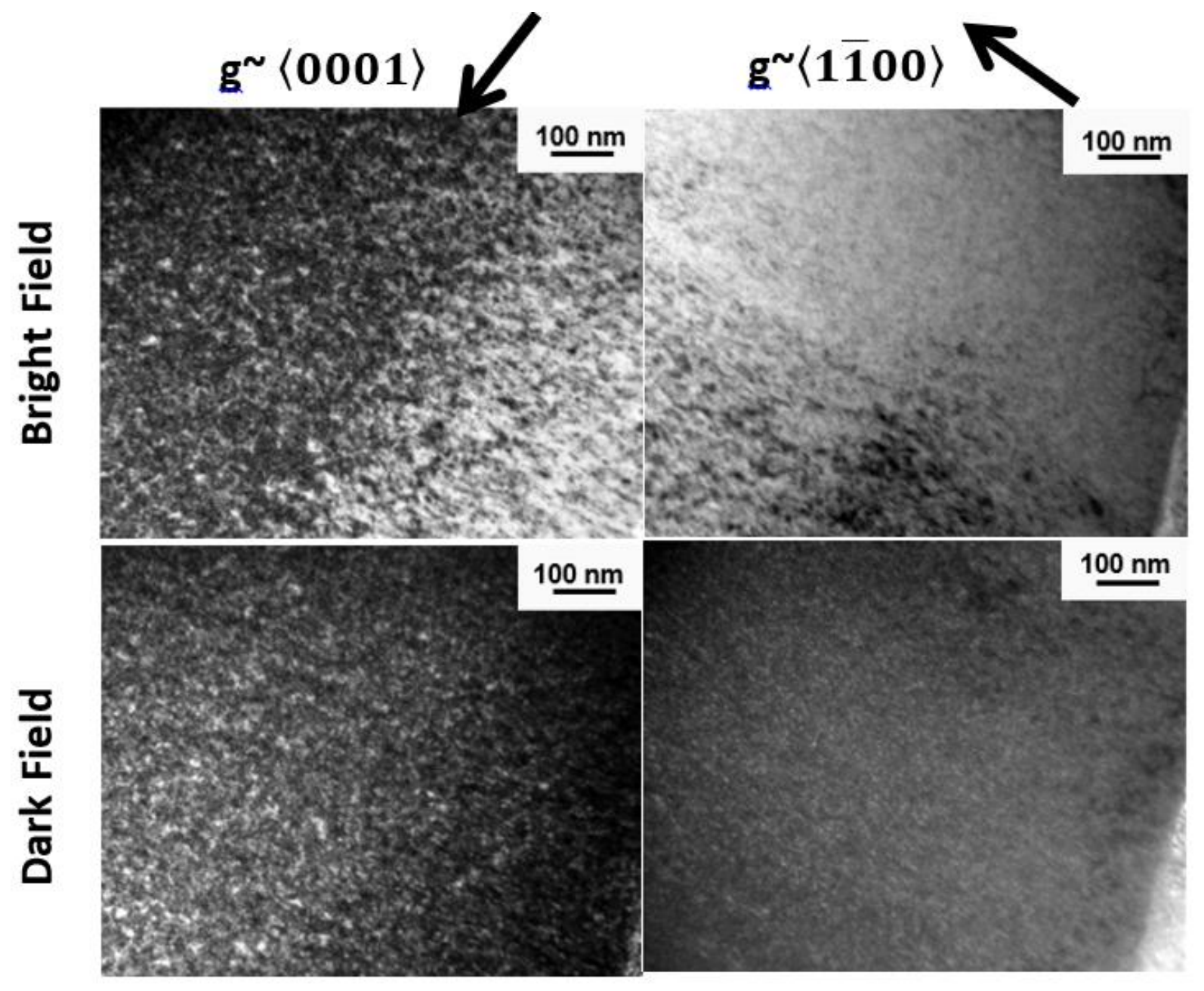

Figure 18 High magnification bright field and dark field cross-sectional TEM micrographs of $5.8 \mathrm{MeV} \mathrm{Ni}$ ions irradiated $\mathrm{Ti}_{3} \mathrm{AlC}_{2}$ to a midrange dose of $30 \mathrm{dpa}$ at a temperature of $400^{\circ} \mathrm{C}$. The basal and prism diffraction vector directions are indicated by $\langle 0001\rangle$ and $\langle 1 \overline{1} 00\rangle$ respectively. 


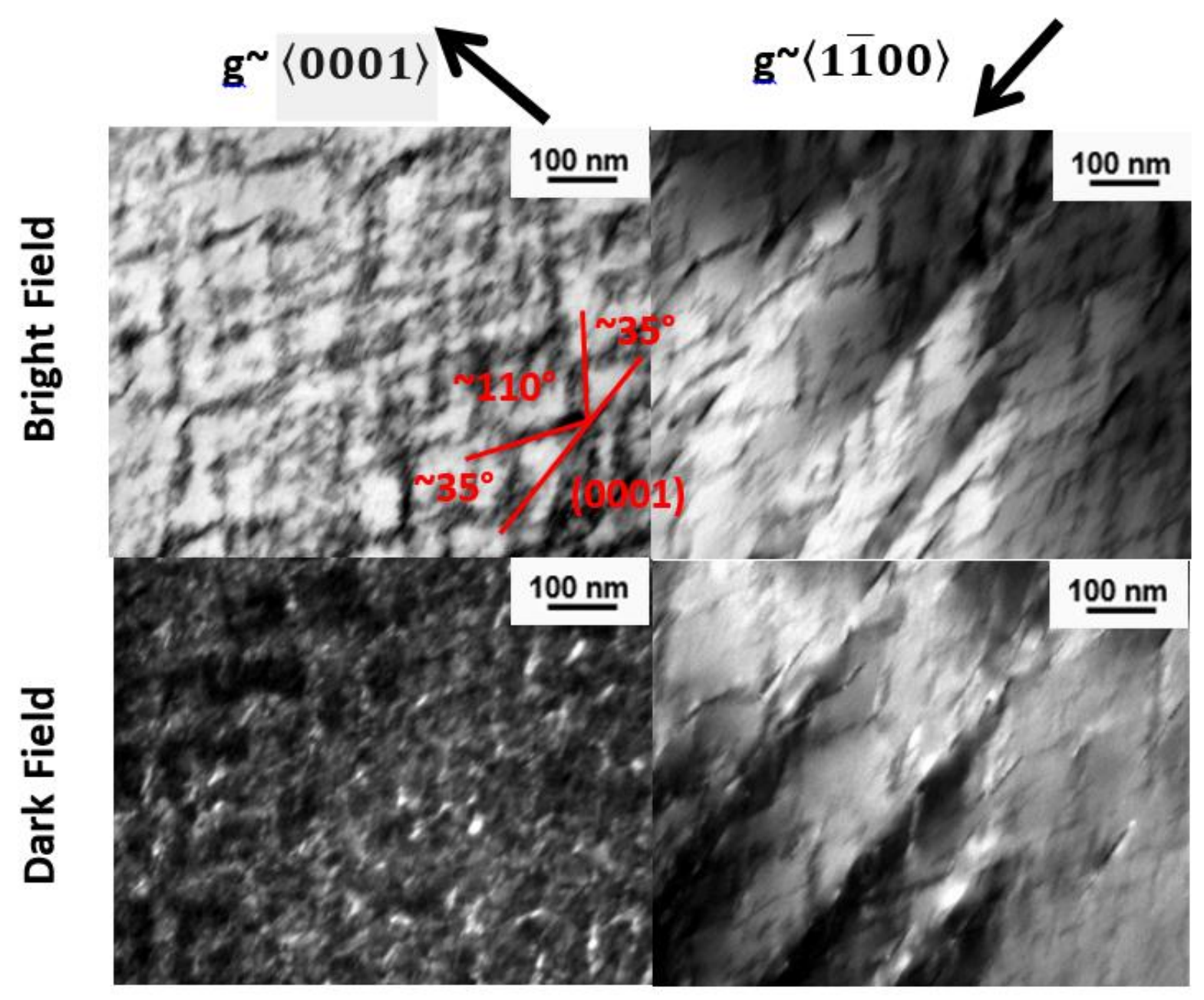

Figure 19 High magnification bright field and dark fieldcross-sectional TEM micrographs of $5.8 \mathrm{MeV} \mathrm{Ni}$ ions irradiated $\mathrm{Ti}_{3} \mathrm{AlC}_{2}$ to a midrange dose of $30 \mathrm{dpa}$ at a temperature of $700{ }^{\circ} \mathrm{C}$. The diffraction vectors are indicated by $\langle 0001\rangle$ and $\langle 1 \overline{1} 00\rangle$ respectively. The red marking show the estimated stacking sequence of small defects with respect to the basal plane. 


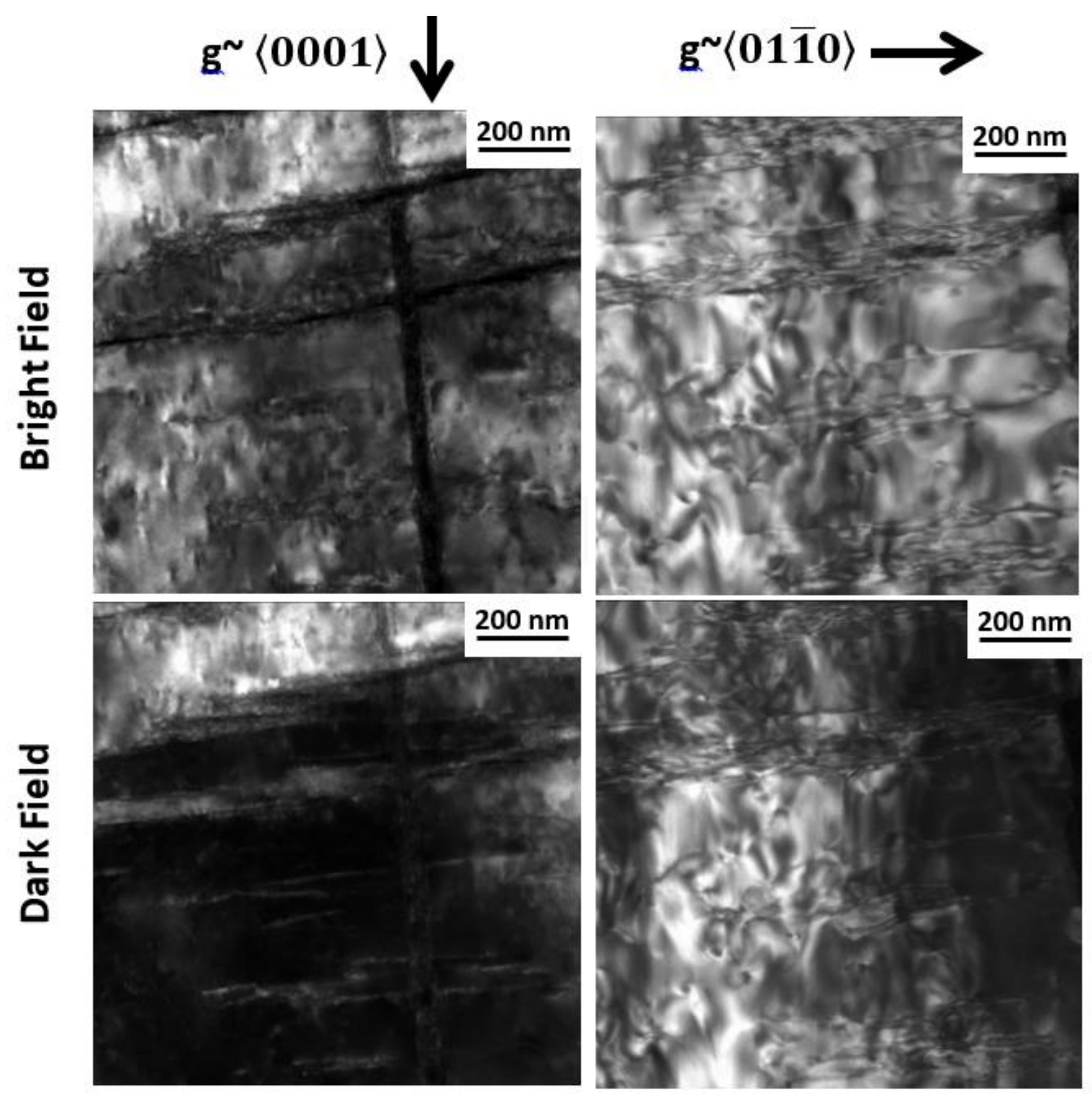

Figure 20 High magnification bright field and dark field cross-sectional TEM micrographs of $5.8 \mathrm{MeV} \mathrm{Ni}$ ions irradiated $\mathrm{Ti}_{3} \mathrm{SiC}_{2}$ to a midrange dose of $30 \mathrm{dpa}$ at a temperature of $700{ }^{\circ} \mathrm{C}$. The diffraction vectors are indicated by $\langle 0001\rangle$ and $\langle 01 \overline{1} 0\rangle$ respectively. 


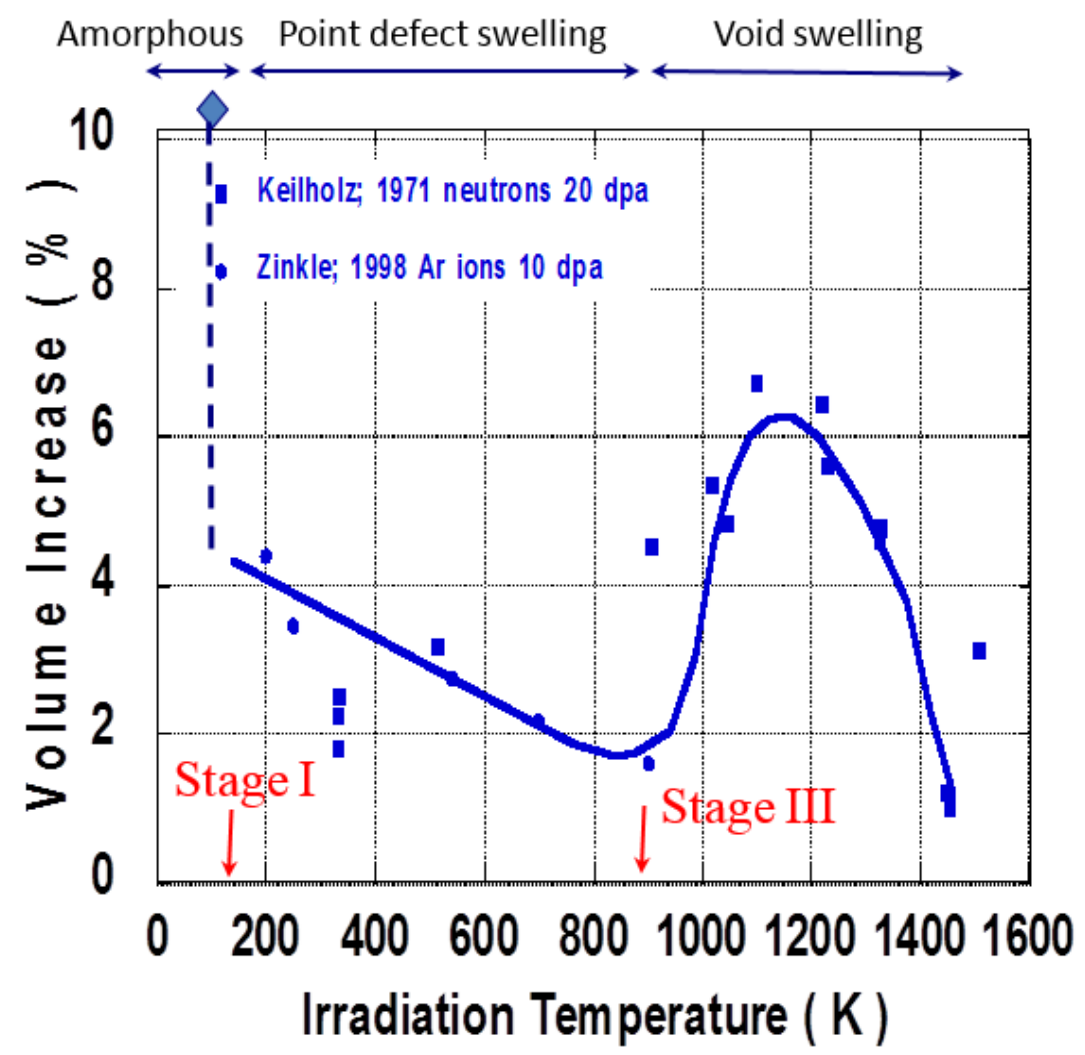

Figure 21 Volumetric swelling regimes for irradiated $\mathrm{Al}_{2} \mathrm{O}_{3}[40]$. 

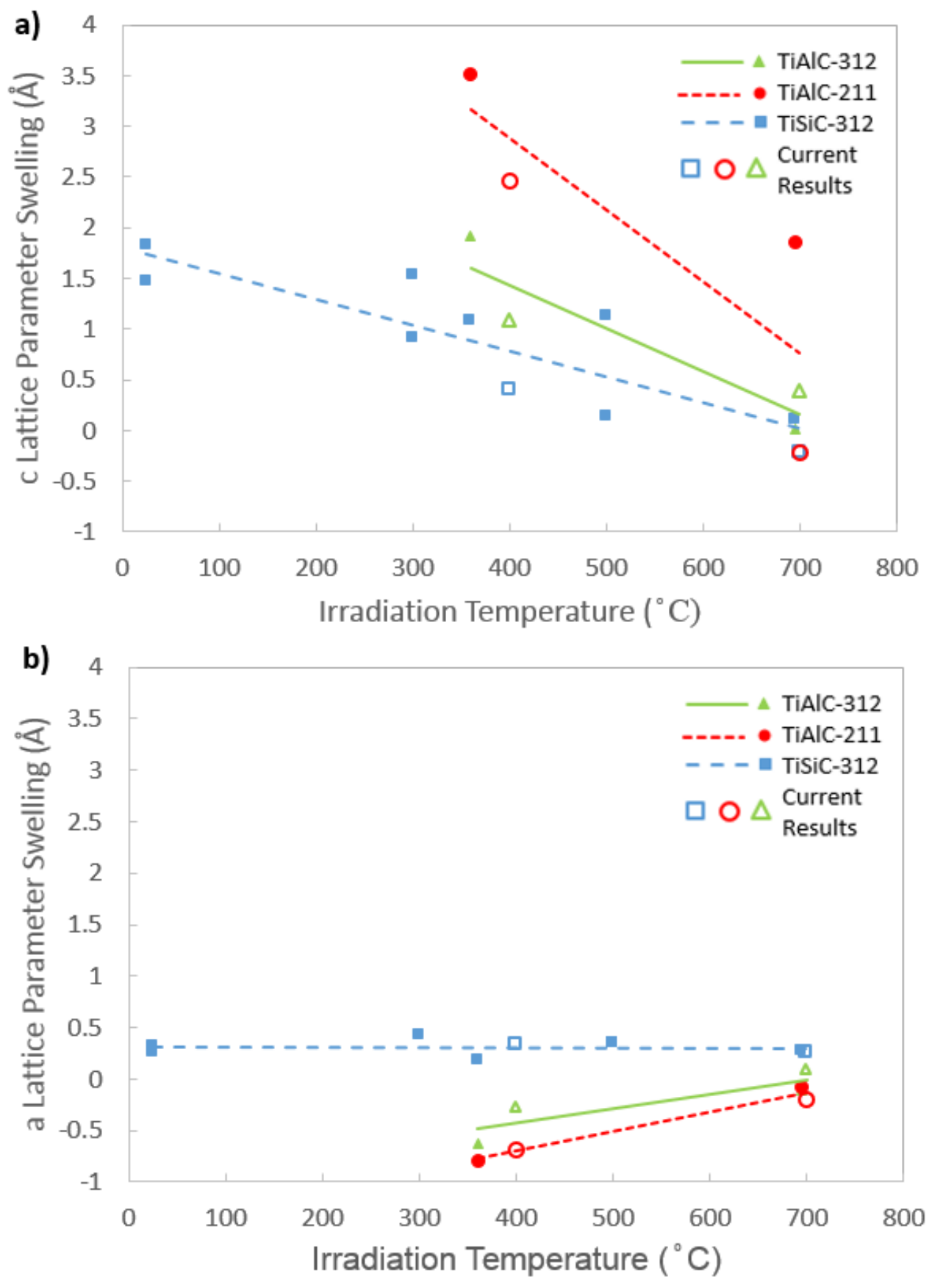

Figure 22 Comprehensive plot of (a) c lattice parameter swelling and (b) a lattice parameter swelling as a function of irradiation temperature for ion irradiated $\mathrm{Ti}_{3} \mathrm{AlC}_{2}$, $\mathrm{Ti}_{2} \mathrm{AIC}$, and $\mathrm{Ti}_{3} \mathrm{SiC}_{2}$. Empty symbols represent the current results, filled symbols represent previous results from literature, and lines represent fits to combined data [14, $16,20]$. 


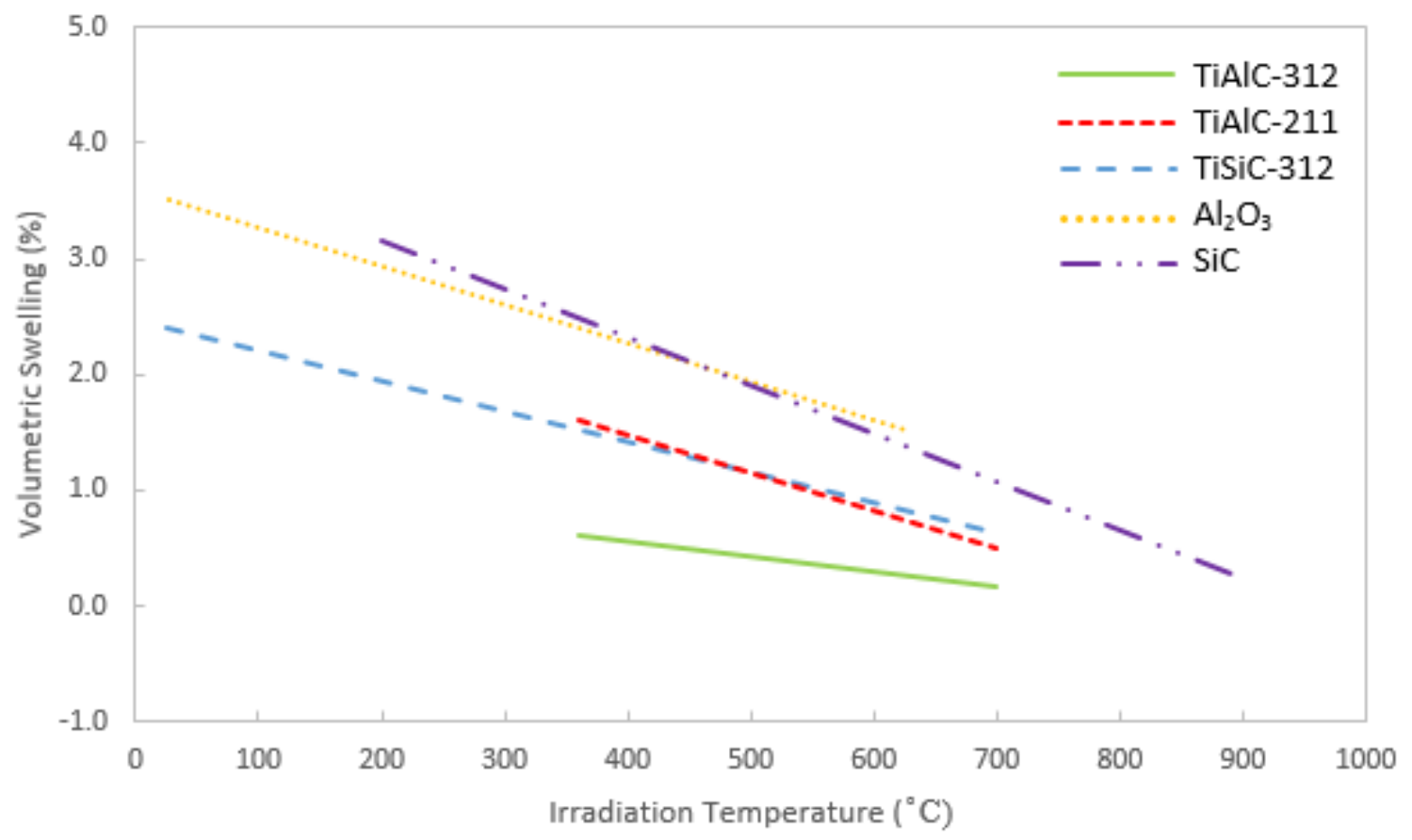

Figure 23 Comprehensive plot of fitted total volumetric swelling as a function of irradiation temperature for irradiated $\mathrm{Ti}_{3} \mathrm{AlC}_{2}, \mathrm{Ti}_{2} \mathrm{AlC}, \mathrm{Ti}_{3} \mathrm{SiC}_{2}, \mathrm{Al}_{2} \mathrm{O}_{3}$, and $\mathrm{SiC}[14,16,20$, 40, 42]. 
High Temperature Ion Irradiation Effects in MAX Phase Ceramics

Aluminum MAX phases $\left(\mathrm{Ti}_{3} \mathrm{AlC}_{2}, \mathrm{Ti}_{2} \mathrm{AIC}\right)$ are not fit for application in irradiation environments near $400^{\circ} \mathrm{C}$ due to anisotropic swelling that induces cracking, whereas the $\mathrm{Ti}_{3} \mathrm{SiC}_{2} \mathrm{MAX}$ phase is overall more damage tolerant at $400-700^{\circ} \mathrm{C}$.
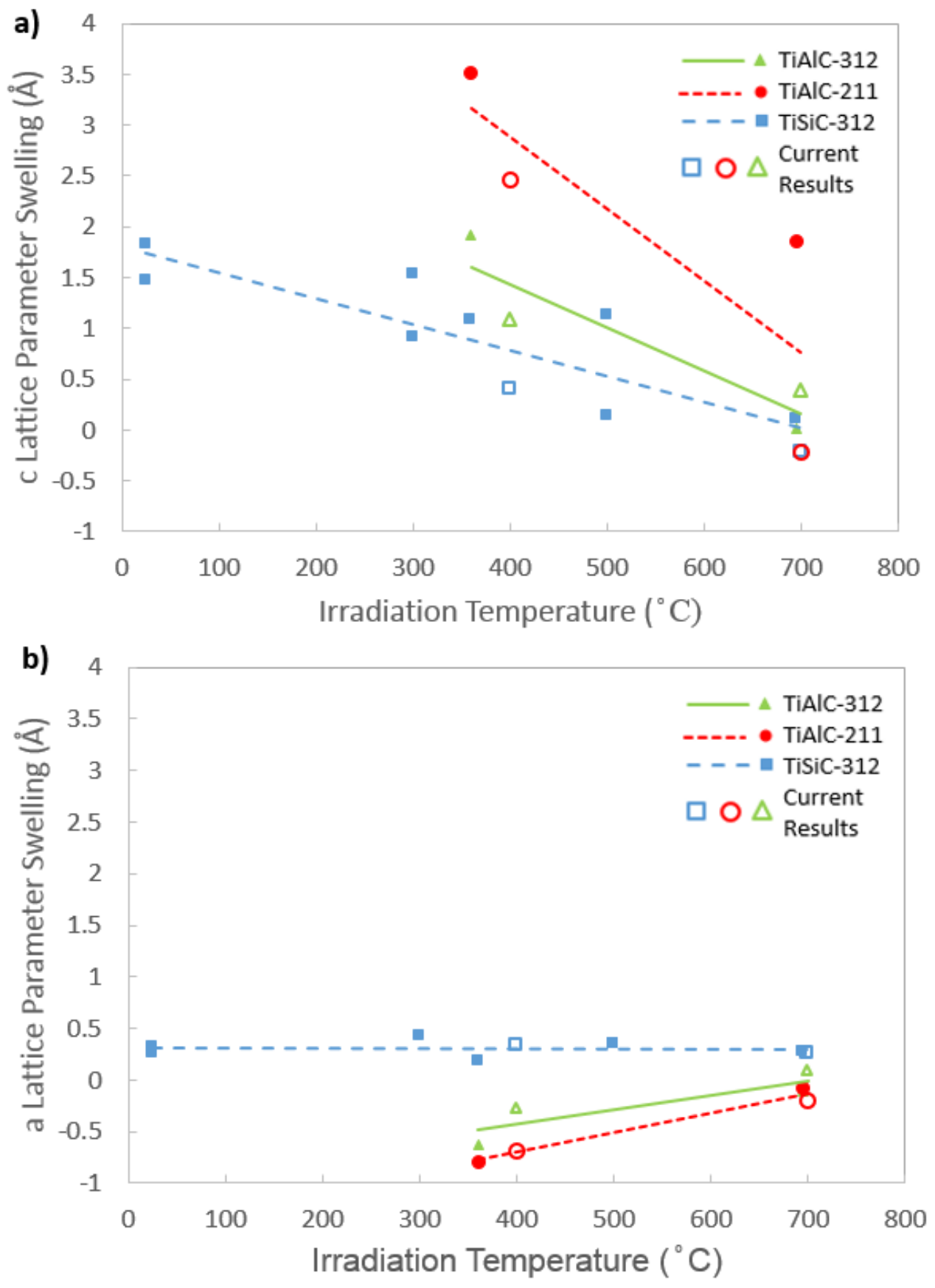